\title{
Trauma-Focused Dynamic Therapy Model in Treating Complex Psychological Trauma
}

\author{
Vito Zepinic \\ PsychClinic P/L, London, UK \\ Email: vito@psychclinic.net
}

How to cite this paper: Zepinic, V. (2017). Trauma-Focused Dynamic Therapy Model in Treating Complex Psychological Trauma. Psychology, 8, 2059-2101. https://doi.org/10.4236/psych.2017.813132

Received: October 5, 2017

Accepted: November 5, 2017

Published: November 8, 2017

Copyright $\odot 2017$ by author and Scientific Research Publishing Inc. This work is licensed under the Creative Commons Attribution International License (CC BY 4.0).

http://creativecommons.org/licenses/by/4.0/

\begin{abstract}
Complex psychological trauma affects all structures of the personality-one's image of the self, images of the others, and one's values and ideals, and leads to the sense that the personality coherence and continuity is assaulted and systematically broken down. Complex trauma, such as war-related trauma, severe brutal rape, kidnaping, terrorism, etc., overwhelms the ordinary human adaptations to life and involves the threats to life and bodily integrity, and confronts human being with the extremities of helplessness and terror, and evokes response of catastrophe. As the complex trauma is a specific traumatic experience, it requires specifically designed trauma-focused therapeutic approach which should deal with: a) the nature of the predisposing factors in complex trauma, b) the manner in which trauma experience and conditioning produce distortions in trauma victim's personality, c) the relationship between the personality structure and trauma, d) the constituents of inner conflicts, e) meaning function and manifestations of trauma syndrome, $f$ ) the structure of the psychic apparatus, and g) the mechanisms of defences. The Dynamic Therapy model has been developed as a three-phase treatment while providing therapy for over decade to the complex PTSD patients whose condition has been an aftermath of human-designed disasters (wars, brutal rapes, assaults and serious violence). The Dynamic Therapy model emphasises that there is a complex process in interactions between different phenomenological components of the complex trauma and that there is a variety of the ways in which etiological factors can contribute to the onset of the trauma syndrome. With the patient's complicated clinical presentations, the therapy accentuates the main principles and targets in treating complex trauma syndrome: 1) trauma symptoms reduction and stabilisation, 2) processing of traumatic memories, dissociation, and emotions, and 3) life integration after trauma processing. The model is a goal-directed phased treatment towards the restoration of a disrupted sense of self that affects the inner and the outer world of a traumatised individual.
\end{abstract}




\section{Keywords}

Complex Trauma, Imagery Exposure, Dissociation, Dynamic Therapy, Mirroring, Self-at-Worst, Trauma-Focused Therapy, Traumatic Memories

\section{Introduction}

Without any doubt, the impact of complex traumatic experience is quite severe on a victim's personality with the deepest feelings of powerlessness, hopelessness and helplessness. The critical point is often a fear for the survival and lack of basic life conditions, and help. Complex psychological trauma leaves scars upon one's personality often a long after the trauma is over; it could be the life-long endless suffering. Most clinicians (Cloitre, Courtois, Drozdek, Foa, Ford, Herman, Resick, van der Kolk, Wilson, etc.) are of opinion that any therapeutic approach to the complex trauma should be trauma-focused and multimodal intervention. While the trauma-focused therapies target PTSD symptoms and outcomes of the traumatic experience, the multimodal interventions address a variety of issues such as ongoing psychological difficulties, physical health, attachment, psychological functioning, and acculturation problems (Zepinic, 2011).

When the diagnosis of PTSD was for the first time introduced as a diagnosis in DSM-III (APA, 1980), some therapeutic methods for phobias, anxiety, and depression had already been developed. The research as well as the therapeutic approach for PTSD benefited from these advances and then rapidly developed a range of the therapy methods (models) for PTSD, in particularly modified existing CBT into a trauma-focused model. However, the clinicians who pioneered the systematic application of in viva for the phobias and anxiety have realised that such therapeutic approach is not applicable for most severe PTSD cases.

Resick \& Schnicke (1992) were the first clinicians who introduced an imaginal exposure developing the cognitive restructuring model to the treatment of PTSD. Since, several other clinicians have developed other models that involve a range of exposure and cognitive interventions. Shapiro (1989) developed eye movement desensitisation and reprocessing (EMDR) method which includes a brief exposure to trauma-related images while patients track the therapist's rapid finger movements with their eyes. Other clinicians had applied principles of the anxiety and stress management to the trauma-focused therapies for PTSD. However, not all therapies are effective in treating PTSD, in particular complex trauma syndrome, but, in general, the trauma-focused methods are more effective than other treatments (cognitive, behavioural, hypnotherapy, supportive therapy, etc.).

Early developed trauma-focused CBT, such as a prolonged exposure (Foa \& Rothbaum, 1998) was predominantly focused on sexual assault in women. This raised the question of whether this method also works in other traumatised populations. With some modified techniques, the trauma-focused CBT in many 
countries has been recommended as the treatment of choice in mixed trauma populations, and special population such as refugees, or survivors of early sexual abuse. Clark (2004) described an approach that was helpful in using CBT for PTSD which involves: 1) identifying core cognitive abnormalities in the disorder; 2) developing a theory of the maintenance of the disorder; 3 ) testing the theory with experiments and prospective longitudinal studies; 4) developing a focused version of CT that targets the cognitive abnormality and maintaining factors; and 5) testing the efficacy and effectiveness in randomised controlled trials and dissemination studies.

While identifying core cognitive abnormalities and developing a cognitive model of PTSD, the close attention to the phenomenology to the disorder is identifying treatment targets and clear understanding of the disorder making differentiation between the severity and the complexity of the symptoms (Herman, 1992; Van der Kolk et al., 1986; Zepinic, 2011). Few issues are noteworthy in regards to traumatic experience: 1) many people recover after traumatic event(s) without treatment; 2) in general, PTSD is characterised by anxiety and fears, although other emotions such as shame, guilt, sadness and anger are often present; and 3) the re-experiencing symptoms and traumatic memories in PTSD have several features that distinguish them from other autobiographical memories (Zepinic, 2011). Some epidemiological studies show that many people do not develop symptoms of PTSD as an aftermath of the traumatic experience, and a large proportion of those who show initial symptoms (acute stress) recover without interventions (Van der Kolk et al., 1986). Thus, the factors why some people develop symptoms of PTSD are a relevant question for treatment, as reversing these factors is likely lead to recovery.

Many symptoms of PTSD, such as avoidance and hypervigilance, are anxiety symptoms and, by the DSM diagnostic criteria, anxiety is a result of appraisals relating to impeding threats. This puzzles many clinicians in whether PTSD is a disorder in which symptoms of traumatic memories are of something that already happened, and why so many anxiety and fears still exist. Ehlers \& Clark (2000) suggested that this puzzle can be resolved by the assumption that persistent symptoms of PTSD appear only in those traumatised individuals who had been exposed to real life threat. In clinical practice, it is evident that perceived threat and fears of another trauma could be found by two sources: 1) people with chronic PTSD show negative appraisals of the traumatic experience and its sequelae; and 2) deep, often unconscious, traumatic memories cause re-experiencing trauma symptoms (Zepinic, 2008).

Re-experiencing trauma symptoms is an involuntary process (Duckworth \& Follete, 2012; Ehlers \& Clark, 2000; Zepinic, 2008, 2011) with four aspects:

1) Re-experiencing lacks the one's awareness of the self in the past ("there-and-then" circumstances), and the sensations and perceptions appear as they were happening in the present threat ("here-and-now" circumstances);

2) Re-experiencing can take a form of affect without recollection (unconscious 
"inner impulse drives"), where emotional responses are triggered without a simultaneous recollection of the traumatic event(s);

3) During the re-experiencing, people do not access other information from memory that would be relevant and meaningful; and

4) Many stimuli may trigger spontaneously intrusive memories, and the connection to the traumatic experience is often a sensory rather than the meaningful nature (e.g., sounds, colour, smell) if it bears resemblance to something present during trauma event(s). The intrusions appear to come out of the blue and the patient has difficulties to spot the triggers for that.

The above stated is important in assessing and planning treatment for complex trauma sufferers. It is common that despite vivid re-experiencing aspects of the trauma, the patients often have difficulty intentionally retrieving complete traumatic memories of the event. Their intentional recall of the trauma event could be fragmented and partial, and disjoined; the important details could be missed and recalling is often in temporal order of the event. People with complex PTSD have disturbances in autobiographical memory characterised by poor (inaccurate) elaboration, strong associative learning and perceptual holding (Zepinic, 2008). This poor elaboration leads to the disjoined fragmentation and poor intentional re-call and weak inhibition of cue-driven retrieval. Negative appraisals of the trauma experience and its sequelae (e.g., rumination, thought suppression, dissociation, safety-seeking behaviour) indicate development of chronic PTSD. We emphasised that the extreme traumatic event(s) generally have severe and complex long-term impact upon the trauma-survivor's personality which is often driven by the inner conflicts power out of the patient's control.

Trauma-focused therapies elaborate that associative learning and perceptual priming are involuntary memories triggered by matching cues with emotion responses or behaviours that do not recollect the trauma itself. Further, the idiosyncratic appraisals motivate a range of the dysfunctional behaviours and cognitive strategies that are intended to reduce the level of a current threat, but still maintain current PTSD. The therapies emphasise that therapy strategies are to reduce threat in form of 1) preventing elaboration of the trauma memory (e.g., avoidance to talk about the traumatic event), 2) preventing reappraisals (e.g., hypervigilance to threat or excessive precautions maintain in beliefs that another trauma is inevitable), 3) increasing PTSD symptoms directly (e.g., suppression of intrusive memories may lead to paradoxical increases of intrusion frequency), and 4) by several of these pathways (e.g., rumination may lead to increased intrusions and maintain appraisals such as about permanent change for worse).

\section{Concept Strategy of the Trauma-Focused Therapy}

Bisson et al. (2007) identified 38 randomised controlled trails of psychological treatment for PTSD. All trauma-focused therapeutic approaches can be more or less effective in treating traumatised individuals, such as the refugees, although 
most studies focused on the CBT effectiveness and its benefit above the other therapies. The effectiveness of some treatment is usually supported by the metaanalysis of particular sample; however, the evidence is not strong enough to recommend which therapy is the most clinically effective. Bisson et al. (2007) stated that there was limited evidence that trauma-focused CBT and/or EMDR are superior to supportive/non-directive treatments, and it is unlikely that their effectiveness is due to non-specific factors such as attention.

Any therapy to traumatised individuals should not only focus on current symptomatology but to other aspects of the patient's life. Most post-traumatic stress patients show other stress-related symptomatology and general approach to complex issues show clinically important effects on PTSD symptoms, depression, anxiety, or dissociation. Most clinicians (Cloitre, Courtois, Foa, Ford, Horowitz, van der Kolk, Wilson, Zepinic, Zlotnick, etc.) are agreed that individually delivered trauma-focused therapy is more effective than a group therapy. In essence, the trauma-focused therapy, regardless of the type, should specifically address the patient's troubling traumatic memories of the traumatic event and the personal meanings of the event and its aftermaths.

There are clear clinical diversities between the stress-focused therapies in regard to their techniques, heterogeneity, applicability, and limitations. One of the most important notice that should be taken into account in providing therapy to traumatised patients is applicability of in viva exposure. The application of different therapies partially depends on their impact on clinical diversity, but not all trails within the same group used identical interventions. There is some limited evidence that shows better outcomes of one therapy upon others or more favourable therapy results for the interventions. Interestingly, the female-only studies show better results in therapy or better response to trauma-focused therapy than the male-only studies. It may be that the female-only studies used more effective interventions and that the trauma of rape is more responsive than the other traumas to the trauma-focused therapy (Foa \& Rothbaum, 1998), or that, for some reason(s), women are more responsive to the therapy than men. It is also interesting that similar superiority in female response has been found for pharmacological treatment of PTSD. However, the studies revealed that the worst results in treating PTSD is among the Vietnam veterans regardless of the type of therapy techniques used (either the trauma-focused models or EMDR). Certainly, in general, combat-related PTSD and these severely traumatised patients are particularly difficult population to treat. Needless to say, a course of trauma-focused psychological treatment should be offered to everyone who has had severe traumatic experience.

In clinical practice, the most evident complex trauma syndrome is among the refugees from war-torn areas. Without any doubt, psychological support to the refugees is a crucial in their recovery and adaptation into new environment. There are many requirements and needs for psychological support in particular with the refugees who came from the war-torn countries. The main goals of the 
psychological support should target changes in refugees' perceptions of self, changes in the experience of their relationships with the others, and changes in one's general philosophy of the life. These goals should lead to the personal strength, new possibilities, relating to others, appreciation of the life, and spiritual changes. Literature and clinical experience throughout the world, in various forms, confirm possibilities for changes in those who struggle with life trauma, suffering, tragedy, and loss.

After few meetings with the clinician or care-person, it is common that severely traumatised patient often summarises ' $I$ am more vulnerable than $I$ thought, but much stronger than I ever imagined. The threat to the assumptive world presented by the major danger can produce cognitive responses that are well known with PTSD sufferers. Typically, with the traumatised refugees there are changes in self-perception reflecting significant disruption in the assumptive world; the experience that the world is a dangerous place, unpredictable, a world in which one's own vulnerability becomes clear and silent. The encounter with a major life challenge can also include inconsistency of the self or self-at-worst level (Zepinic, 2012). The treatment goals should be in developing new interests, new activities, and perhaps embarking on significant new paths in life.

Psychological support should be multidimensional grasping understanding of the trauma-survivor's personality changes, emotional, cognitive, and attachment distortions. It is usually a long-term intervention that required flexible frequency meetings with the patient. The goal of intervention is to achieve an emotional and cognitive regulation, inter and intrapersonal effectiveness, tolerance to distress imposed by the inner conflict drives and the traumatic memories, coping strategies, and self-management (Courtois \& Ford, 2009; Herman, 1992; Zepinic, 2010).

Those who provide psychological support should communicate clearly and together with the patient to identify trauma symptoms, comorbid condition, and possibility to resolve them. Clear explanation about the symptomatology is the first step in psychological support helping patient to develop alliance with the clinicians. The traumatised patients are usually confused and significantly troubled by own condition and often have some ideas that are added to the mystery and threat of their disturbed personality and functioning. For them it is important to recognise eventual exaggeration of comorbid condition, automatic thinking, or maladaptive emotions or behaviours. The patient's numerous complaints often create confusion as to where to start and what could be achieved throughout the psychological support. However, the most important is the patients' safety (Herman, 1992) as they often have misconceptions about comorbid condition and correcting this could be one of the first tasks. Most severely traumatised patients often believe that trauma symptoms cannot be healed and they lost a contact with reality, reporting extreme hopelessness and desperation.

After identifying the main problems, the clinician should deal with the main complaints which could be of the minimal impact upon the patient's personality 
but it is nominated as one's excessive concern and priority. To effectively helping patients to understand own problems, the clinician should possess a solid understanding of the background of the problem and its aftermaths. However, it is important to know that every trauma-patient is an individual case, presumably as a result of the individual variations in predisposition or vulnerability to trauma syndrome. The clinician should look for common signs of the patient's condition and make a sense of the individual suffering, but avoid extensive generalisation.

Any approach in providing psychological help to the severely traumatised patients should deal with the following concepts: 1) the nature of the predisposing factors in one's trauma condition; 2) the manner in which the trauma experience and conditioning produce the distortions in the trauma victim's personality; 3 ) the relationship between the personality structure and trauma; 4) the constituents of inner conflicts and their aftermath; 5) meaning, function and manifestations of the trauma syndrome; 6) the structure of the psychic apparatus, and 7) the mechanism of defences.

Traumatised patients show dysregulation in the areas of emotions, thoughts, behaviour, intra and interpersonal relationships. They are very emotionally sensitive and experience intense emotions, often out of control, which could last for a long period of time after the trauma experience. They can be compared with those patients who suffered severe burns and have no 'emotional skin' to protect them from the painful feelings. They often cannot make clear and sensitive distinction between who must be responsible for their comorbid condition: their own vulnerable self or other disturbances. This is a key point in providing psychological help for the patient's 'insight' while the clinician attempts to introduce changes and reinforce self-valuation and self-continuity.

The practical framework for any psychological help should be found on disturbed emotions, shattered sense of the self ('self-at-worst'), broken relatedness, and unconscious traumatic memories which blocks the patient's functions in the sphere of self (Zepinic, 1997). As an aftermath of the self-structure disturbances by trauma, the traumatised individual's spirit is broken down, diminished, with the affective state flat and non-expressive, lifeless, empty, and vacuous. The individual may express a sense of identity diffusion, fragility, and a strong feeling of discontinuity with a severe disruption in regard to intrapsychic and interpersonal relationships. Severely traumatised patients often report being exposed to the traumatic event(s) which is outside the normal range of the human comprehension. Traumatic injuries to the self-identity of the traumatised individuals can be quite catastrophic (irreparable), causing perception that their unity and wholeness are lost due to highly stressful event(s).

In clinical practice, there are several developed guidelines for treating complex PTSD, and most guidelines do not include treatment of dissociative states nor problems of individuals who had been exposed to prolonged and repeated trauma commonly referred to as complex PTSD. In general, guidelines recom- 
mend an individual treatment of the trauma victims with rear involvement of those who could take co-therapist role in supporting effectiveness of the treatment (Zepinic \& Kuzmanovski, 2015). The complex trauma is an extreme experience that tends to occur within the refugees from war-torn countries or in those who had been interrogated and tortured either as a subject of political violence or war prisoners. They would refer a life-threatening experience with an unescapable condition with only goal to survive. They usually describe constant and intense fear for the life often repeated and for a prolonged period of time (Zepinic, 2004).

Clinical experiences tell us that different types of trauma experience cause differences in severity and complexity of suffered symptoms which makes needs for individual approach to every single case. Some of the trauma victims will report predominantly psychosomatic or neurological problems (e.g., chest pain, stiffness, heart palpitations, sweating, trembling, blurred vision, hot and cold flushes, paraesthesia) which, in essence, do not have anything common physiologically, but psychologically. They will also report a fear of dying, losing control, or sexual dysfunctions, etc., what further complicate their nature of psychological distress. Constant, but unreasonable, fear is usually reported as one's outcomes of being directly threatened with dangerous and a life-threatening experience. Consistent with such experience, the fear is an alarm reaction, and intense push to escape from a potential danger in which the organism is mobilised, both physically and psychologically, for an action (fight or flight response). As fear does not have real threat, the fear reaction is called a 'false alarm' but for the patient is so horrible that he cannot escape. That condition is a 'biological vulnerability' which causes fear in the absence of any specific trigger (APA, 2013).

Following the stressful life events, patients with complex PTSD are more vulnerable and might develop physical symptoms in response to the extreme trauma experiences (Briere \& Spinazola, 2009; Courtois \& Ford, 2009; Herman, 1992; Horowitz, 1978; Silova, 2002; Van der Kolk et al., 1986; Wilson, 2006; Zepinic, 2012). With severely traumatised patients, the therapeutic alliance is an essential factor in the therapy as it is the overall bond between the therapist and the patient evolving during the process of provided therapy. Although there is no a single definition of the therapeutic alliance it could be seen as an agreement on task and goals, role investment, empathic resonance, mutual affirmation, and a therapeutic bond. In clinical practice with the severely traumatised individuals, a stronger alliance is seen as an important factor for more effective treatment outcomes (Zepinic, 2011).

Subsequent to their constant fear, in the absence of real danger, some severely traumatised patients could report panic attacks as a vicious cycle of inescapable condition-fear of an imminent physical and/or psychological disaster arising from the misinterpretation of a certain bodily sensation and/or psychological experience. The treatment should be designed to break the vicious cycle by providing corrective information and experiences that result in the re-attribution of 
an unpleasant psychological affective phenomenon in non-pathological and safe circumstances. It is, in particular, important to identify the most feared physical signs that may cause the patient's panic attacks. Patients usually describe their panic attacks as embarrassing and/or humiliating-the misery of dramatic variations of intense, unpleasant, and strange experience. We classified these panic experiences into four groups (Zepinic \& Kuzmanovski, 2015):

a) Qualitative different reactions from previous experience, distorted and unreal loss of normal sensations in the patient's extremities or in the interior of their body (feelings of heavy or weightless body experience of peculiar sensations or the paraesthesia in upper or lower limbs);

b) Frightening aspect of the panic such as loss of controls that the individual has always taken for granted (e.g., struggle to retain or regain voluntary control over focusing, concentration, attention, and action; difficulty in focusing extends into a sense that they are losing consciousness; difficulty framing thoughts or pursuing a consistent logical line in the thinking or reasoning);

c) Confusion and disorientation;

d) Automatic suppression of reasoning the powers (frightening ideas, losing control, chocking), and feeling of being engulfed by an uncontrollable anxiety (this feeling has been described as 'unendurable pain' and 'the worst imagined experience').

Apparently, those trauma victims who had been exposed to the prolonged and/or repeated severe trauma often show not only symptoms of complex PTSD but other disturbances of their psyche. It seems that most of them suffer rather syndromal than simple disorder and that therapeutic approach should aim therapy for the complex issues. So, any therapeutic guidelines for PTSD should be accompanied with the therapy models treating accompanied symptoms of depression, anxiety, dissociation, or some psychotic features. The specific goals of the therapy should compile clinical and empirical knowledge about trauma survivors and effects of the complex trauma and its treatment (Cloitre, et al., 2012). Further, many clinicians (Cloitre, Courtois, Ford, Herman, Pelcovitz, Resick, van der Kolk, Wilson, Zepinic) are agreed that complex trauma is a syndrome not a single disorder and, as such, needs combined therapeutic approaches. The selection of therapeutic models depends of a range of symptoms organised into a conceptually coherent diagnostic description of the complex trauma as a syndrome (Zepinic, 2011).

Certainly, any definition of the complex PTSD includes the core symptoms of PTSD (re-experiencing, avoidance/numbing, and hyperarousal) in conjunction with a range of other clinical features. In essence, the symptoms of complex trauma could be grouped into five broad domains: 1) emotion regulation difficulties, 2) disturbances in relational capacities, 3) alterations in attention and consciousness, 4) adversely affected belief systems, and 5) somatic distress or disorganisation (Zepinic, 2010). Complex PTSD is typically result of the exposure to repeated or prolonged instances or multiple forms of interpersonal 
trauma, often occurring under circumstances where escape is not possible due to physical, psychological, family, environmental, maturational, or social constrains (Herman, 1992).

The symptoms profile of complex PTSD recognises the loss of emotional, social, cognitive and psychological competencies that deteriorated significantly as an aftermath of the trauma experiences. Subsequently, the treatment of complex PTSD emphasises not only reduction of psychiatric symptoms, but equally, improvement in key functional capacities for the self-regulation and strengthening of the psychosocial and the environmental resources. Loss of psychosocial resources (e.g., reduced self-efficacy, prosocial behaviours, social support) is common and these losses contribute to the severity and chronicity of PTSD symptoms over time (Zepinic, 2016a).

\section{Conceptual Framework of the Dynamic Therapy Model}

Everything stated above should be incorporated into any therapy model designed to treating severely traumatised individuals. Changing how they feel, think, and act along with rebuilding self-acceptance should be therapy goals. Accepting the patient's strengths as well as weaknesses without a sense of shame or embarrassment is focused goal in therapy. The principles of restoring the patient's intra and interpersonal relatedness, self-cohesion and continuity remain a central focus to the recovery process.

There are different recommended treatment models for treating complex PTSD with general agreement that treatment should be staged or phased oriented, each with a distinct function. Based on clinical experience in providing therapy to severely traumatised patients for over a decade, Zepinic (2001) developed the Dynamic Therapy three-phased model in treating complex trauma syndrome which applies to holotropic integration of the distorted self into a whole (Zepinic, 2004, 2011, 2012, 2016b). The main concept of the Dynamic Therapy model includes three treatment goals: a) restoration of a form of relatedness ("Interconnectivity"), b) restoration of a sense of the aliveness/vitality ("Dynamism"), and c) restoration of an awareness of self and inner events ("Insight'). The theoretical concept is based on clinical experience that disturbances of the self-structure-one's image of the body and sense of self-caused by severe trauma leads to a sense that coherence and continuity of the self is systematically broken down. Severe trauma overwhelms the ordinary human adaptation and resistance as it usually involves the threat to life or bodily integrity and confronts the trauma victims with the extremities of the helplessness, hopelessness, and terror, and evokes the response of catastrophe.

Disturbances of the self-structure may cause a sense of an identity diffusion, fragility, and feelings of the self-discontinuity, with severe disruption in one's psychological equilibrium and interpersonal relationships. Such trauma experience lies outside the normal range of a human comprehension and cannot be assimilated in part because it threatens the basic assumptions about the one's sense 
of self and his place in the world. These assumptions include distorted trauma victim's personal safety, integrity, self-worth, and self-continuity (Zepinic, 2011). The psychological sequalae following traumatic experience are usually a dominolike progression of the stress-response reactions. The process of disintegration of the trauma victim's self may occur in two ways: a) consciously expressed concerns related to the weak, vulnerable, and defective sense of self, and b) out of the person's conscious awareness, disintegrated self is seen as a danger to the traumatised person and to the others. As consequences of the self-discontinuity, the trauma victim is flooded with intrusive memories of the traumatic experience, as well as thoughts, images, and dreams with the compounded levels of hyperarousal or flashbacks (Van der Hart et al., 2006; Wilson, 2006; Zepinic, 2012).

Treating disintegrated self is a very complex issue, in particular using the standard trauma-focused therapeutic approaches. The standard practice of debriefing after either natural or man-made disaster and catastrophes, severe fears or phobias after terrorist attack, brutal rape, or combat experience, could strike further development of the complex stress-related condition because of re-traumatisation of the fresh traumatic experience. There is a united agreement among the clinicians that those who had been exposed to the severe, repetitive, or prolonged stressors should be seen as they are under risk of suffering complex trauma syndrome. To explain trauma symptoms, it is important to consider how much exposure to a life-threatening situation became conditioned to a wide variety of stimuli during the traumatic experience. As the severe trauma inflicts a terror and fear which are increased by the inconsistent and unpredictable outbursts of the enforcement against the victim's self, the trauma inevitable leads to the loses of one's autonomy and all aspects of the independent functioning, and even basic desire to survive (Zepinic, 2015).

To understand the theory of the complex trauma syndrome, it is necessary to clarify the traumatic event as an external event, causing severe psychological and/or physical upheaval with its lasting and crushing consequences of the victim's inner state of the self and its fragmentation. The sense of self and self-object loss is seen as the key to the physiology of traumatisation, and the stressor event and the self-system as ancillary to such losses (Ford et al., 2005). Those who are victimised, in particular by the man-made trauma, are unable to understand, accept, or comprehend the trauma experience: they rather would disappear, if possible, from the real world which to them seems quite unsupportive, hopeless, and even dangerous place for leaving (Burgess et al., 1985; Foa \& Rothbaum, 1998).

In essence, the complex trauma paradigm is unique and differs from the thesis of single stress disorder diagnostic features (Allen, 2005; Courtois \& Ford, 2009; Herman, 1992; Van der Kolk et al., 1986; Zepinic, 2011). When planning treatment for complex trauma patient, it is important to take into account the diagnostic conceptualisation of the complex trauma syndrome characterised by three 
main domains (Zepinic, 2011):

1) The repeated reliving of traumatic memories which involves intense sensory and visual memories of the traumatic event accompanied by an extreme physiological and psychological distress and feelings of an emotional numbing. The intrusive memories can occur spontaneously or can be triggered by a range of real or symbolic stimuli;

2) Avoidance of the reminders of the trauma-numbing, detachment, and emotional blunting which coexist with an intrusive recollection of the event. Intrusions are associated with an inability to react and experience a joy and pleasure, commonly followed by total withdrawal from any engagement in life; and

3) Increased arousal with the hypervigilance, irritability, memory and concentration dysfunctions, sleep disturbances (nightmares), flashbacks, and an exaggerated startle response. Traumatised people are easily distressed and distracted by any unexpected stimulus; their perceptions are excessively focused on the search in finding the similarities between the present and their traumatic past, usually reinterpreting neutral experience associated with the traumatic event(s).

Dynamic Therapy model assumes that posttraumatic growth of traumatised self is based on three main aims: 1) changes in the perception of self, 2) changes in the experience of relationship with others, and 3) changes in one's general sense of purpose. Those victims who had been exposed to a severe stress experience usually present wane, weakness, loss, diminished, and destruction of their psychic equilibrium with severely decreased sense of compassion and a critical view towards the outer world. Patients report feelings that they are "island" and not "part of main". They need a greater sense of the relatedness, closeness, and free to be again "the self", having desirable motivation to restore their own self strangled by the trauma experience.

In providing psychological support to severely traumatised individuals it is often necessary to modulate different approaches, methods and therapy techniques than to provide a specific trauma-focused single therapy model. It should be rather designed process of treatment, than provided some special technique, used as a basis for intervention and explicitly given as the rationale for the individual treatment. Suitability for using the Dynamic Therapy model in healing the one's traumatised self is based on focusing attention upon the symptoms of the complex trauma syndrome, affects and behaviours, and one's destructed sense of the personal being. The Dynamic Therapy model applies to a holotropic ${ }^{1}$ (oriented toward the wholeness or moving in the direction of wholeness), integration of the consciousness and the self.

The main aims in using this model in treating severely traumatised individuals is based on following therapeutic aims (Zepinic, 2011, 2015): 1) restoration of a form of the relatedness ("Interconnectivity"), 2) restoration of a sense of aliveness/ vitality ("Dynamism"), and 3) restoration of an awareness of self and inner events (“Insight").

${ }^{1}$ From Greek holos, meaning "whole", and trepein, meaning "moving toward or in the direction of something". 
Interconnectivity is an attempt to restore the core negative aftermaths of the trauma upon victims: disempowerment and disconnection from the self and others. The trauma survivor is in position to face tasks for creating a new future, new relatedness between the inner and the outer world, and to rebuild a new self which has been distorted by trauma experience. However, feeling of helplessness and isolation are often the strongest barriers in achieving the targeted goals: patient's empowerment and reconnection. With sustained self-related disturbances, traumatised individual interferes both with new engagements and resolving issues with trauma attachment figures or perpetrator. Disturbances related to maladaptive fears and shame are interrelated and therapy should transform such disturbances related to the social environment (insecure and vulnerable to harm and/or worthless, and vulnerability to rejection and abandonment). Interventions for complex trauma syndrome patients in form of challenging the catastrophic (fearful) expectations additionally address difficulties with interpersonal fears and distrust.

Therapy should bring an understanding that the post-trauma symptoms represent patient's pathological exaggeration of a "dangerous world" and that the trauma survivor does not need "to protect himself from a danger". All fears and anxiety are related to the trauma symptoms and inner conflicts that prevent the patient from rebuilding a sense of power and control. On one level, self-exposure to the outer world with still existing inner conflicts can be seen as another re-enactment of the traumatic experience. Severely traumatised individuals often feel insecure in a social environment and have a fear of being hurt by others again. The inner conflicts separate trauma victims from the outer world and made them withdrawn, isolated, and incapable for any relatedness. The therapy should provide learning as to how to control the bodily and emotional responses, and the inner impulses that bring the patients into uncertainty of a new relatedness with the outer world.

The sense of inevitable harm is organised around the fear, dread, and a chronic anticipation of a danger that generates into possible new relatedness. Thus, the patients should learn to overcome the danger and be empowered to the feelings that not every danger (internal or external) is an overwhelming experience and that not all fear and anxiety is terrible or threatening. Just as they must overcome their own fears and inner conflicts, they must also overcome these external social pressures; otherwise, they will be continually subjected to symbolic repetitions of the trauma in everyday life (Herman, 1992). This sense of the vulnerability can lead to an anticipating danger and catastrophic expectations due to the complex self-(dis)organisation and the perpetual feelings of disconnectedness.

Dynamism is seen as a transformation from altered and dysfunctional identity caused by the trauma experience into a functional one. It is not surprising for the patients who have experienced severe trauma to discover that disturbances of the psyche are more complex than it was assumed and that the roots of the dis- 
turbances/dysfunction are incomparably deeper. Erikson (1968) spoke about the "identity crisis"- a chaotic and profoundly confused mental state of the combats. While treating soldiers for battle neurosis, he stated that all of them "did not know any more who they are... there was a distinct loss of ego identity... the sense of sameness and continuity and the belief in one's social role was gone". The outer and inner world of those who had experienced severe trauma has been shattered-their lives have continuously been inundated with the traumatic images.

The dysfunctional sense of the aliveness/vitality is driven by unconscious needs and wishes from the traumatic past that play a greater role on the traumatised individuals than the present circumstances. Pathological forms of the patient's aliveness/vitality are identified by disturbances or alterations in the normality integrative functions of the memory, identity, or consciousness. In essence, these pathological forms represent one's failure to integrate aspects of perception, memory, identity, and consciousness into the present time creating "feelings of strangeness" or "spacing out". The trauma survivor does not have control over the past (trauma experience is deeply in unconscious memories), and experiences a sense of helplessness and loss of control over the body-self structure (Zepinic, 2016b). This makes a dual function of the same individual delaying integration from the past ("there-and then") into the present time ("here-and-now"). This pathological construct is an aftermath of the trauma which caused discontinuity of life experience.

It is essential not to ignore the facts that the past (trauma experience) plays a huge role in determining the patient's present experience. In a sense that the past holds centre stage and influences the nature of present performances, the therapy should focus on the present time (presentness). In a trauma survivor, the presentness is defective and there is a raptured practice of everyday life which seems difficult and unlikely to move from the influence of the past (Meares, 1987). The roots of this conception appear unconscious, however, they are in the mind-perceptions, sensations, feelings, attachments, memories, dreams, and ideas-capturing a present mental state. Any patient's attempt to explore the external reality corresponds to what is in their mind from the traumatic past.

The trauma experience is mirrored and, when having memory about a past event, whatever happening now is actually a conviction of the traumatic past. The trauma survivor's present time is a "prisoner or hostage" of the past, with no anticipation about the future. The past eclipses the present, casting so strong a shadow that "here-and-now" is always in a shade and presentness can only confirm and affirm what happened in the past. To challenge this is to achieve a psychic equilibrium which the presentness desperately needs. The presentness as a psychological entity, is meaning-oriented and perception-oriented, however, it misses the nature of its consciousness because of unconscious impact from the traumatic past. The phenomenological features cannot be functional as an awareness or consciousness is a necessary condition for the functional present- 
ness.

The presentness is not only just one ongoing experiences, but also it is totally what is going on now. It is a compound of the perceptions, sensations, cognition, affects, feelings, and the actions that presently act upon a traumatised person, consciously or unconsciously. In a sense of vitality is an affective attunement of the presentness, the therapy should bring into action the patient's acting and feelings for "here-and-now" concept. This tentative approach brings the patient to a daily exposure of not the present but the past experience-thoughts, emotions, and perceptions. All domains, modalities, and types of the situations perform a formation of the present framework of vitality and execution: interaction intentions, feelings, and thoughts. The patient's feelings become shaped by the intentions, thoughts, and his feelings of social environment not by the inner conflicts drive. The thoughts become co-created in a dialogue with the others, not by withdrawal or isolation. The mental condition is co-created by the individual's belongings to the social environment changing intrapsychic phenomena which are "stamped" by the traumatic past (Zepinic, 2016a). Therapy should transform the patient's fixed historical past into memories that are present-centered instead of past-centered (Stern, 2004).

Insight is seen as a self-continuity, regardless of the external circumstances or a generalised identity diffusion caused by trauma experience; it is quite an important part of the therapeutic goals in the post-traumatic growth. Horowitz (1978) stated that without a sense of self-coherence and continuity, an individual is more likely to develop symptoms and explosive shifts in state of mind. Self-coherence is essential interpersonal style-it includes integrity and virtues within one's personality. The trauma experience shattered self-continuity and made identity diffusion with different or altered self-representation, split off one part of the self to another, and imposed a general blurring of the self.

An important question is whether the trauma experience universally changes and damages the self-coherence and continuity? It is difficult to answer this question but, with no doubt, traumatic experience brings one or another sort of the identity diffusion and inability. The trauma experience undoubtedly had a cataclysmic impact on an awareness of the self and accumulated negative emotions. Such negative stroke on the self affects a sensitised soil of the self which, over time, becomes relatively limited and discontinued. Often this experience can become so significant that we doubt self-potency in evoking emotional responses. This is because the traumatic experience is a consideration of a series of damaging events and the impact on the self cannot be undervalued (Zepinic, 2016a).

Traumatic experience can impact one's self on two levels: it can be so devastating and destructive that no trauma survivor could be expected to cope with, or can "freeze" any growth and continuity of the self. Under the trauma condition, the capacity to strive, tolerate frustration, to channel aggression into the socially accepted outlets, ability to control inner impulses, and develop inde- 
pendency and self-assertiveness are shattered. In the course of this development by the trauma, the patient is subjected to a lot of frustration that involve abandonment of a cooperative relationship within the group. The patient is not capable of handling such frustration having a great difficulty in relating to others.

The trauma survivors with impacted insight are often rejected and denied of the legitimate demands, making them so overwhelmed by the feelings of helplessness that they will be never able to overrule the inner conflict drives. They are unable to tolerate frustration and/or withstand traumatic experience, which becomes a component of the post-traumatic growth. Such individuals are more likely to react catastrophically to relatively normal hardships than in a controlled way. The insecure patients feel so threatened by rejection or punishment that they will find it necessary to repress such impulses such as hostility towards their own self striving for mastery, independence, and the self-assertion (Zepinic, 2012). Often, repression occurs dramatically following some external stress that convinces the patients that a danger can be real.

Traumatic event(s) constitutes a fear of relatedness between the inner and outer world. The fear will nevertheless persist, aiding the repressive process of the self. In the course of therapy, the recovery of the repressed traumatic experience may ameliorate or dissipate certain symptoms, especially those that serve the function of keeping these memories repressed (Banyard \& Williams, 1998; Herman, 1992; Van der Hart et al., 1993; Van der Kolk et al., 1986; Wilson \& Drozdek, 2004; Zepinic, 2008). The most dramatic results occur in a simple conditioned fear associated with a danger for the physical existence such as accident or injury. This minor affecting stress can be seen like an exposure to unbearable stressors during the natural disasters or war. The recall of forgotten memories becomes fully restored to the previous status (trauma experience).

All symptoms of shattered insight have their origin in lost awareness of the self and they are deep enough into the past, penetrating the myriad conditioning and prevent any new idea from entering the mind. Peering into all influences, it is a demonstration of how each of these symptoms has the power to divide the self into disconnected pieces. The therapy task is to recapture the divided fragments into one functional system. While doing this, the therapist may find, in most cases, that the symptoms themselves will not vanish easily and that the trauma experience will dominate on one's awareness of the self for a long period of time.

The expectations that the recovery of trauma experience will suppress all inner conflicts should be considered cautiously. It is like an infection that operates insidiously on a body over a period of years. The original source of infection can be discovered and treated whilst the infection has already affected other bodily structures. The removal of primary focus can still leave the body infectious, and it is necessary to threat the secondary effects before declaring that the problem is entirely healed. A single experience can likewise act as a focus engendering in an insecure individual a feeling that the world and its people are not to be trusted. 
This is a negative awareness of the self which is seen as being in constant danger of being hurt. By the time, this manner of keeping these conflicts has been structuralised into behaviour so ingrained that recall of the original trauma will have a little effect on habitual responses. The therapy should involve the re-education and reconditioning of the current symptoms originated by the trauma experience.

Often during the therapy, the trauma survivor recovers forgotten memories of the traumatic event(s) and cannot recall considerable amount and details of the trauma experience. He liberates himself from certain associated symptoms; however, the essential difficulties of the self-awareness may still exist at a deep unconscious level. The circumstances that revoke the original traumatic scenes may continue to plague the patient's mind. However, both the therapist and the patient should remain alert for possible re-experiencing of the trauma event that is not a relapse but a part of the residually existing forgotten trauma memories. This can make the patient insecure about the therapy progress and deteriorate the self-awareness and daily interpersonal relationships that were developed (Zepinic, 2016a).

Thus, the essential goals of restoration of awareness of the self and the inner events are not only to recover from the traumatic condition presented and reported as the conscious experience, but also to ascertain why and how the unconscious inner events (conflicts) become so powerful and catastrophic (necessitating repression) that shatter the patient's steps away from the traumatic past (Allen, 2005; Boss, 2006; Courtois \& Ford, 2009; Van der Kolk et al., 1986). These reactions, patterns, and attitudes, derived from the past (traumatic experience) may induce repetitive maladaptive forms of behaviour motivated by a desire to escape from the helplessness, to gratify the essential needs, and to avoid fears, anxiety, and potential hostility. The traumatised individual reacts to the present time with the uncertain mechanisms of adaptation rooted in his past traumatic experience, and current problems are a result of the inner conflicts and external demands, fears, and resentments that arise from the interpersonal relationships.

The psychological interventions to the trauma survivors should provide ways to reduce the compulsive impulses from the past which drive the patients into isolation and a stasis of the self-continuity. These accumulated inner conflicts consequently block the self-development and the self-awareness, diminishing the ability to tolerate anxious expectations. It is a usual autonomic imbalance of complex trauma syndrome accompanied by the effect of anxiety in the chronic form of the disturbances (residual irritability). The repression is an exhausting condition causing trauma victim's rigid fixation on the trauma, typical dream life (dreams of annihilation, defeatism, frustration), contracting of the general level of functioning with the constant fear of outer world, lowered efficiency, disorganised behaviour, lack of coordinated goal activities, profoundly altered functioning in the automatic, motor, or sensory nervous system, general irrita- 
bility, and explosive aggressive reactions.

The trauma victim's overemphasis of the parts influenced by the traumatic past may produce unfortunate effects of the therapy, finding justification for the resistance to changes. The therapy may reduce the compulsive impulses developing the patient's isolation from the present time. Some patients may be led to believe that awareness of their past conditioning will be dissolved by their non-reintegration with the world. Consequently, they will continue to search for stereotyped behaviour of withdrawal accompanied by fear, anxiety, and residual irritability.

Knowledge about roots of the inner conflicts ultimately contributes to understanding the complex trauma syndrome and brings tremendous value in establishing treatment strategy of one's self-continuity recovery. It points to the patient's weakness and sensitivity of the self at the time of the particular trauma experience. It further brings the awareness of repetitive happening (residual irritability) at the present time as a reflection of the unconsciously memorised trauma event. Of particular therapeutic benefit is that self-withstands of the inner conflicts and accompanied negative emotions liberate recall of a trauma experience. During therapy, the patient may report how often he has little respect for his own self because it is overwhelmed by his fears of the past. The traumatised individual is not able to master these fears, impulses, and to tolerate extreme anxiety that causes him to be 'frozen' by the iceberg of the unconsciousness. This has an enhancing impact on vulnerable self, leading to further depletion and inconsistency of the self-structure.

The conceptual framework of psychological interventions using the Dynamic Therapy model to the trauma patients includes the " $C$ " $s$ concept (Zepinic, 2011): connection, creativity, compassion, coping, contingency, co-construction, cohesion, and consciousness. This comprehensive set of the components, rather than presenting an alternative means of the reparation and healing, constitutes complementary elements, all of which need to be applied to the trauma survivors. Even under the optimal conditions, severely traumatised individuals have mixed reactions to the provided therapy and mixed feelings in participating in therapy that can be completely anti-therapeutic.

Connection stems from a need to connect parallel self-operations into a network rather than a sequence. This means that the inner un-relatedness should be found and stored in/inter, and connected into one functional system as a whole and coherent.

Creativity is seen as relating/involving/giving something new than a stereotyped patient's behaviours and relatedness. It is a process of the derivative sublimations: self-representation becomes possible, imagination is enhanced, and an innate mind drives toward the sense of discovering one's real self. This assumption of unity of the individual is an attempt to create a unified personality regardless of the one's life experience (trauma) and forms of expression (traumatised self). The key concepts are: expectations about the future rather than rely- 
ing on the traumatic past; innate tendency to develop capacities to the fullest and to relate with the others; interpret experience; and, alignment with responses instead of suffering.

Compassion is the therapist's approach to a patient's "here-and-now" subjective experience and shows therapy directions (willingness). Conversation between the therapist and the patient should be seen as two arms linked by a movable joint (post-traumatic growth), contriving to accomplish a valued self.

Coping predominantly means successfully meeting challenges in trauma symptoms and dysfunctions impacted by the trauma experience. The patient should use the coping mechanisms while adjusting consciously and unconsciously to the environmental demands. Instead of being an "island", the patient should move to be "part of the main" without altering his goals or purposes.

Contingency is defined as the unfolding therapist-patient relationship, the integral part in the communication/conversation sufficient to elicit the result (healing the traumatised self and made post-traumatic growth). Targeting and fostering "aliveness/togetherness" the therapy aims are correcting one's maladaptive forms of relating.

Co-construction includes the elaboration of unconscious products (dreams, fantasies, etc.) which could be a symbolic expression of the one's past (traumatic) experience. In co-construction, the therapist shares an experience and co-creates into a therapeutic dialogue and relatedness, verbal or non-verbal communication, deepening the sense of clarity and communion.

Complexity is one joined (shared) experience during the therapy; an interpersonal therapist-patient relatedness which enables the traumatised self to achieve more stable, flexible, and more adaptive states. The patient's self is traumatised, depleted or shattered, complicated by a reverse of growth, and idealised figures less formidable as their strength is internalised with the gradual deidealisation ("me and others"). The images are concrete, with resultant distortions and condensations that run into depletion of the self-values.

Cohesion is defined as the sense of self becoming whole but also the action of forming a unit and wholeness, a sense of trust: growing connection between the therapist and the patient towards the post-traumatic growth-the full repair of ruptures, enabling patient to experience a sense of cohesion and coherence across the various states of mind. The therapy is aimed in producing a cohesive self-the stable and adequately structured sense of the one's identity even in the face of having severely traumatised self. The pathology of such self is a mirror reflection of an unstable self whose cohesiveness has experienced severe break-ups. While achieving the cohesive self, the therapy should consist of a progressive consolidation, sensitive and empathic, with the "self-object" figure good enough to support the restoration of ego strength into a self-worth and a self-assertive state.

One of the main principles of the Dynamic Therapy model is that the therapist must be able to communicate clearly and give clear explanation of the pa- 
tient's suffered complex trauma syndrome at the first session and reiterate it throughout the therapy adding new information about comorbid condition. Clear case formulation is also part of the therapeutic approach helping the patient to develop a therapeutic alliance and cooperation though the therapy. Severely traumatised individuals are usually confused and troubled by their complex trauma syndrome and often have some ideas that add to the mystery and threat of their disturbed personality and functioning. However, for the patient, it is important to recognise eventual exaggeration of the comorbid condition, automatic thinking, and/or maladaptive emotions and behaviour.

The patient's numerous complaints about symptoms often create confusion as to where to start and what could be achieved throughout the therapy. However, the most important task in any therapeutic approach is the patient's safety. Inevitable, the severely traumatised patient has misconception about comorbid condition and correcting this could be also one of the first tasks of the therapy. The patient often believes that the complex trauma syndrome cannot be healed and that he loses contact with reality, reporting an extreme helplessness and desperation. In such situation, psychological intervention should deal with the following concepts: a) the nature of the predisposing factors in complex trauma, b) the manner in which the trauma experience and conditioning produce distortions of the trauma victim's personality, c) the relationship between the personality structure and trauma, d) the constituents of inner conflicts, e) meaning, function and manifestations of the complex trauma syndrome, f) the structure of the psychic apparatus, and g) the mechanisms of defence.

Psychological therapies for severely traumatised individuals should focus on the effects of traumatic experience on their prior self-object experiences, self-values, altered experience of safety, and loss of the self-cohesiveness. This helps the patients to maintain and identify a dysfunctional sense of self in the face of trauma experience. The therapy should address the subjective and interpersonal sustaining factors of the trauma aftermath (e.g., issues in trust of the outer world, shattered assumptions about attachments), as well as changes in the beliefs that the external world is a dangerous place. The severely traumatised patient has widely altered perceptions related to the feeling that a threat is inevitable. This is a chronic state that requires employing a mixture of the supportive and insight-oriented interventions, based on the individual's symptoms, developmental history, personality, and an ability to tolerate exploration of the trauma effects.

As it was stated earlier, in treating severely traumatised individuals it is common in using three-phase models of the therapy, individually designed and based on the assessment findings. The phasic treatment models do not have sharp line between the therapy phases-they are interconnected and often overlap with no clear red line when one phase ends and another commences. In general, the heart of therapeutic approach is sharing with the patient formulation of the complex trauma syndrome symptomatology, to elicit feedback of the therapy 
sessions, and make necessary adjustment during the therapy (Zepinic, 2011, 2016a). The Dynamic Therapy model cannot be strictly regarded as a specific theoretical concept (e.g., psychoanalytic cognitive, behavioural) but it uses the suitable elements from the different therapeutic techniques and models putting them into one effective approach.

Taking into account aftermath of severe traumatisation, it is common that trauma victim's inner conflicts drive is unconscious creating fears, anxiety, and enhanced resistance and, indeed of battering down the patient's resistances using the cognitive restructuring. The therapy should give a freedom to recall when the patient feels capable of handling traumatic memories. Some of the traumatic memories, due to their painful nature, can be forgotten but they are quite important as they can induce inner conflicts at any time. However, during the therapy the patient cannot be forced to revoke them from amnestic state but has to leave them until a stage the patient gains full control over the inner conflicts. When achieving such stage, the forgotten memories then will not have any more catastrophic impact on the patient's inner world, and the patient is able to tolerate and control isolated fragments of these memories.

The Dynamic Therapy model is: a) goal-directed towards specific objectives caused by the trauma experience, b) it is organised around a relationship between the therapist and the patient, c) it includes continuation of the assessment and case formulation, and d) it evokes emotional responses in the patient which ought to be therapeutically handled. The goals in treatment consists of a relied of trauma symptoms and better adaptation in areas of living in which the patient has failed, reorganisation of the attitudes and values within expansion of the personality assets, and an alteration of the basic structure of the one's character with creation of potentialities that were thwarted by trauma.

\section{a) Early phase of treatment}

Early phase of treatment includes aiming elements of an impulse containment, the patient's engagement, and condition stabilisation. Regardless of the actual resources of referral for psychological therapy, the most trauma patients come for therapy at time when defences are broken and evidenced "here-and-now" dysfunction. Many of trauma survivors report that, up to one year after the traumatic event was over, they functioned within their "ups and downs", in essence being aware that the trauma is not over for them. Their maladaptive feelings and traumatic memories become more impacting on their everyday life, their relatedness, and self-conception.

At the time requesting treatment, the patient's coping resources are usually overstretched and everything in life is overwhelmed by horrible memories. They report dysfunction or even total loss in many domains-struggles in relations with the others, complaints regarding social relationships, having arguments or tense reactions with loved ones or even with the own self. Some report that loneliness and alienation, as well as avoidance by others, was "red light" to seek the treatment. Their past, present, and future have become somatically, emotionally, 
and cognitively confused-the reactivated traumatic memories in the form of intrusive affects and bodily sensations signal danger even in peaceful moments (Ogden et al., 2006).

Trauma patients usually report avoidance in daily life with their attention focused mainly on threat cues or on internal dysregulation. They also report spending a little or no time thinking about their relationships, emotions, and maladaptive psychological factors that affect their everyday life. They get "accustomed" to be aside, isolated, and withdrawn and for them it is easy to continue along with trajectory than to change. They often do not see a meaningful connection between their traumatic past and present time, still being in "there-and-then" than "here-and-now" circumstances.

The therapist has a very tough task of deciding from which standpoint to start the therapy. However, it is advisable in the early phase of treatment not to start exploring the traumatic memories as the patient is not ready for such complex therapeutic task and has not yet developed a close relationship. Instead, in the early phase the interventions should focus on stabilising the patient's physical and psychological state, emphasising the self-regulatory skills that maintain arousal within the therapeutic frame of tolerance, and reducing the self-destructive tendencies and behaviours. Developing resources for stabilisation and the patient's integrative capacity for adaptive functioning in daily life increase the patient's safety and faith that help is really available. The therapist's role is to evaluate with the patient to understand why the patient's condition is dysfunctional. The patient becomes aware of the reality of his weakness and this is an important component in helping him to accept that his vulnerability should be treated.

We emphasise that the early phase of treatment should help the patient to recognise the dysregulating emotions, arousal, and behaviour that can cause selfdestructive reactions such as the self-harm, violence, dangerous activities, or any other forms of maladaptive behaviour. This make the therapist overtake the role of a regulator of the patient's dysfunctional mental state, to adjust the pace and therapeutic process to help the patient to develop resources for a self-regulatory system.

The early phase of treatment involves the reinstatement of lost resources, strengthening existing or inventing new resources (personal skills, abilities, relationships). This will help the patient to facilitate the self-regulations, a sense of the self-competence and resilience. Development of new resources or capacities should start with the acknowledgment and recognition of the existing resources such as the patient's ability to operate cognitively, as well as recognition of "survival skills" that enabled the patient to cope with the post-traumatic challenges. Developing resources will help the patient to face and integrate the traumatic memories and foster competence and creativity to meet life's challenges.

During the early phase of treatment, one of the main tasks is to observe unconscious conflicts and the types of defences employed by the patient, which form a blueprint of the unconscious problems. In fact, this blueprint point 
should be utilised during the entire therapy provided. Since the repression is threatened by the process of exploring the fears, anxiety and unconsciousness, the therapy appears in supporting and stimulating the defensive mechanisms. These actions cause resistance to productivity and narrative that consequently may hold up the therapy progress and patient's cooperation with the therapy endeavour. Such resistances are dealt with the patient's interpretation of the external world (which is a "dangerous and unsafe place"), and own self (which is disported and shattered).

The therapist takes on the role of bringing patient to an awareness of how and why he is resisting, and the inner conflicts that make resistance and defences necessary. Thus, sooner or later, the patient will transform past attitudes and feelings into a present therapeutic relationship with the therapist. Good therapeutic relationship is a basic rule, an attack on the resistance and the defences that will change the meaning of proper the therapist-patient relatedness. As the therapeutic relationship progresses, the patient will gradually remove habitual protective devices and facades that could create to maintain the conventional relationships.

Shaping therapeutic relationship is a key point of the therapy considering that for the patient is not easy to talk about trauma that brings back to the feelings of terror or rage endangered by the trauma experience. Two essential goals must be achieved in therapeutic alliance: positive relationship and a sense of working together. The therapeutic alliance includes an active collaboration leading to the patient's feeling that the therapy is a working together towards common goals with the therapist's guidance and support.

In the early phase of treatment, with its theoretical and practical constructs, the therapy deals with: a) the nature of one's maladaptive relatedness, b) the manner in which the traumatic experience produced distortions in the personality structures (the self), c) the constituents of the inner conflicts, d) the meaning, functioning, and manifestations of the trauma experience (Zepinic, 2011). All these elements play a role in shaping the therapeutic relationship and most clinicians agreed that the early phase is the most important and complex as it includes a dealing with the overwhelming emotions and the pathological operations. The early phase is also a stabilisation phase in which the therapist deals with: identifying and labelling emotions; identifying and appropriately utilising social supports; focusing on the content rather than affects; scheduling, planning, and anticipating daily activities; making judicious use of exercise and food; and engaging in relaxation and stress inoculation exercises (Herman, 1992; Van der Hart et al., 1993; Zepinic, 2016a). All of these are part to establish the patient's trust and a feeling of the acceptance-the therapist is trustworthy, reliable, and striving to be helpful.

Early phase of treatment is a period when the therapist teaches the patient to evaluate own resources that might be used as a benefit by directing awareness to body sensations, areas of the tension or relaxation, movement, pain, discomfort, 
structure, and alignment. Patient should evaluate which of his capacities are functional and which need challenging. While we examine the authentic nature of the disturbed attitudes, we realise that the patient has been victimised by the trauma symptoms endlessly, again and again, during and after the trauma. This imposed a threat to his dependency needs and personal security, created a devaluated self, and impaired relationships with the others. The patient believes that he is unable to undertake any responsibilities on his own shoulders as he is too vulnerable and week to bear the burden of normality. As he is unable to manage the crisis and fears, his psychic equilibrium is disrupted threatening his mastery and precipitating the catastrophic fears and anticipations of further danger.

Due to the patient's vulnerability and psychological weakness, sometime physical too, the patient assumes a very passive role, exhibiting little or no spontaneity and initiative and anticipating that his needs and demands cannot be fulfilled. His helplessness and fears add further psychological injury until the act of going to therapy creates challenges which bring back his capacities. Thus, this would serve to bring the patient to an awareness of the maladaptive attitudes and patterns that he habitually demonstrates in order to defend his weakness. It is of therapeutic benefit if the patient is able to recall the traumatic past that impacted such dysfunctional state and present defected levels of functioning, experience, patterns, competences, and strength.

The opening therapy sessions in the early phase of treatment should be seen as the meeting between two human beings-one who needs help and expects it and another who is able to provide help and is willing to do that (Zepinic, 2011). It is common notice nervousness when the patient entering into therapy, even when entering into the clinician's office, with evident his tension and anxiety, and the body language that shows an emotional response to the therapy-gait peculiarities, fidgetiness while sitting in the chair, wringing of the hands, picking of the skin and lips, stiffening of posture, clenching of the fist, tapping of the toes and grimness in the facial expressions. The therapist should always bear in mind that the severely traumatised individual is stigmatic, anxious, uncertain, and with a lot of anxiety and fears towards the therapy.

It is important that the therapist checks his own non-verbal expression to ascertain that he is not conveying disapproval, boredom, or irritation. Reassurance that therapist will do his best helping the patient to restore his disturbed psychological equilibrium is usually given in a verbal form, however, it is also stated in the therapist's non-verbal behaviour by maintaining a calm and the objective attitudes. The reassurance should not be used straightaway when the therapy starts as the patient may not yet have sufficient faith in the therapist to be convinced of the security. The patient may imagine that the therapist does not know how serious the condition really is or that he delivers therapy without deep confidence. If therapist gives the reassurance, it should be after listening carefully and respectively to what the patient points out. The patient will appreciate the 
therapist's listening even if some of the patient's comments are senseless of objections about therapy or clinician are premature.

One of the most needed reassurance in the early phase is that the patient is not going to be insane, seen as common thoughts in severely traumatised patients. Panicky feelings, bizarre impulses, cognitive dysfunctions, and a sense of unreality and uncertainty lead the patient to such assumptions. Because of the evidenced dysfunctions, he becomes convinced that he will lose control of mind and perhaps inflict an injury on himself or on others. The patient may attempt to justify his fear of insanity be revealing that he had trauma experience in which many people become insane although they were mentally stronger than the patient. He will attempt to convince the therapist that the torture and horror imposed was so painful and unbearable that insanity must follow that. Under no circumstances should the patient be ridiculed because of this fear and the therapist essentially should show that the fear of insanity is a common post-trauma symptom. The patient should be reassured that he did not provide some evidence, neither reported symptoms, that insanity is a forthcoming state.

The most common reassurance needed for brutally raped victims is in regard to aspects of the individual's sexual life (Burgess et al., 1985; Foa \& Rothbaum, 1998). Frigidity or loss of sexual desire, for instance, is the major concern of many sexually abused victims. Projecting their sexual dysfunction, some women tend to blame their sexual identity as a reason of being raped and current sexual incompetence. In therapy, this misconception has to be carefully clarified with a therapy focused on the trauma experience rather than on the sexual dysfunction. In men who were sexually abused as a child, or in any other circumstances (commonly seen during war imprisonment), reassurance may be required in cases of the temporary impotence. This reassurance may be organised around the theme and episodes of the impotence, mostly focused on the trauma experience which has eventually been constant danger and an insult upon the person's dignity. These conditions normally inhibit real sexual desire, and the trauma victim's memories and sense of tension also inhibits one's sexual performances thereafter. With meaningful reassurance, the therapist strengthens the patient's sense of self and self-values, which are quite important for therapy in general.

If reported, it is recommended to work on dissociation in the early phase of treatment, and this should continue through the entire therapy. Dissociation is generally described as an altered state of the patient's consciousness which results in a diminished awareness of the environmental events (Courtois \& Ford, 2009; Van der Hart et al., 2006; Zepinic, 2016a). The last edition of the DSM-5 (APA, 2013) clarified dissociative reactions (depersonalisation and derealisation) caused by severe trauma experience creating profound disturbances of the traumatised personality. History of multiple types of traumatic events, chronicity and severity of trauma symptoms appear to be associated with the dissociative reactions. Putnam (1989) stated that while treating over 70 combat veterans, they reported having experienced in the extreme detachment and depersonalisa- 
tion during moment when they thought they were about to die or when they killed others. He was of opinion that depersonalisation syndrome frequently occurs in those trauma survivors who had been exposed to severe trauma or a life-threatening experience.

As a part of the early phase, the patient's safety is focused on endangered feelings of the disturbed self. This vulnerability becomes extreme in dissociative state when the trauma victim feels terrorised by dissociation (Allen, 2005; Van der Hart et al., 2006; Zepinic, 2011). Herman (1992) stated that establishing safety is the first priority in treatment and she has emphasised the therapist's role in catering to the basic needs without exposing the patient on a danger of an abuse at the hands of own self and others. Although suicidality is not diagnostic criterion for PTSD, in clinical practice this condition is often presented in particular with those traumatised patients who have experienced prolonged or repeated trauma. Severely traumatised individuals may find suicide as an "emergency solution" in order to escape from the "persistent trauma" that continues into a post-trauma time (Zepinic, 2015). Depleted or shattered self has been afflicted with a sense of emptiness in painful intensity of traumatic memories, and "self-at-worst" is not able to cope with negative feelings as "nothing is inside" (Banyard \& Williams, 1998; Ford, 2009; Summerfield, 2001; Wilson, 2006; Zepinic, 2016a).

There is no boundary when the therapy should move from the early phase of treatment into another one and this is more hypothetical than the practical question. It is the therapist's judgment to estimate the patient's completion of the early phase and readiness for the next phase bearing in mind that every patient has individual response and progress. In general, the transition should be gradual, not hurried, and a few therapy sessions can be used to overlap two phases. It is a golden rule that clinical experience is never limited and it is never completed. At some point, the problems treated and already solved in the early phase may re-occur later, in particular when some trauma events are reminded by a trigger factor(s) causing temporary regression or relapse in the patient's condition.

\section{b) Mid-phase of treatment}

The mid-phase of treatment focuses on deepening understanding of the trauma symptoms that also includes recalling traumatic memories related to the specific trauma experience. Traumatic memory system is organised as a complex structure of cognition, emotions, and tendencies to respond. Some clinicians (Meares, 1987; Putnam, 1989; Van der Hart et al., 2006) suggested that dissociation is a "coping strategy" that arises from the experience of extreme helplessness in the face of the trauma. They also found that an early dissociative response has been found to predict a worse outcome of the trauma. Hyer et al. (1996) in a study of 110 hospitalised Vietnam veterans found that a chronic PTSD led to the use of emotion-focused and escape-avoidance strategies to cope with the traumatic memories. The traumatic memory system can be triggered by 
contextual cues which resemble the original trauma. These cues are usually external in their nature and might be produced by an object, person, circumstances, or even by a conversation. The therapist should bear in mind that trauma memories are split off the patient's conscious awareness and stored as sensory perceptions, obsessive thoughts, and behavioural enactment. Because the trauma is not recollected as a coherent, autobiographical narrative, the trauma patients are unable to deal with the effects and implications of their memories by discussing or thinking about them.

As the patient's safety was treating aim in the early phase of treatment, these issues should continue through the mid-phase, in particular when the trauma patient releases details about the trauma memories. Anything that threatens to disturb an individual's solution of the core conflict arouses a fear. Descending into this condition more and more and withdrawing from the "here-and-now" circumstances often creates proviso for suicide (Zepinic, 2001). The rise of anxiety and fear of the traumatic memory and the inner impulses may result in both aggressive and repressive behaviour. While talking about the traumatic memories, the individual's emotional pain might be an overwhelming experience from the perspective of the helpless trauma patients who become unable to tolerate and deal effectively with any kind of loss or pain. They cannot tolerate re-trauma and they are desperate to get out of it.

Many clinicians (Courtois \& Ford, 2009; Foa et al., 2009; Herman, 1992; Van der Kolk et al., 1986; Zepinic, 2008; among others) are united in opinion that therapy on the traumatic memories is fundamental for the entire treatment of trauma-related symptoms. Effective processing of the traumatic experience requires specific therapeutic efforts and failure to adequately process the traumatic memories inevitable leads to a chronic psychopathology. It is proposed (Zepinic, 2015) that PTSD becomes treatment resistant condition when the patients process the trauma in a way that retains a sense of persistent threat or danger.

As desensitisation process in PTSD cannot be used in vivo exposure, many guidelines (including Dynamic Therapy model) for the effective treatment of a severe (complex) PTSD recommend employment of the modified imagery exposure technique. In complex trauma syndrome, treating traumatic memories is quite complex and sensitive matter which could cause re-traumatisation. The aim of imagery exposure is to help the patient to confront fear and/or traumaevoking stimuli and weaken distressing thoughts, emotions, and somatic arousal associated with the trauma event(s) through the habituation and the correction of catastrophic misinterpretation of the presence, and also significance of such experience. Although the exposure sometimes still may evoke fearful thoughts (e.g., imagination of a certain person, time, or place), this exposure gradually 'expose' the patient to traumatic moments and desensitise catastrophic reactions.

The therapist should identify risk and protective factors and discuss these issues with the patient before starting to work on the traumatic memories. Treatment of complex trauma syndrome and release of traumatic memories cannot be 
unrealistic promise that a "therapy will work"-otherwise condition of regression may occur with further 'encapsulation' of the inner conflicts and traumatic memories. The therapist should bear in mind the patient's fear of releasing traumatic memories because of risk for re-traumatisation. Overcoming fears of the traumatic memories involve gradual and one guided approach that is directed by the therapist's and the patient's work to transform the memories into a symbolic verbal account that is personified and presentified. This realisation results in an autobiographical narrative memory of the traumatic event(s) and in actions that can be adapted to the present time rather than to the traumatic past (Van der Hart et al., 2006; Van der Kolk \& Courtois, 2005).

Before commencing therapy on traumatic memories, the therapist should review eventual existence of symptoms that could contraindicate works such as psychotic features, fixation on lower action tendencies, malignant regression, the physical conditions that lower the mental capacity, some ongoing distress, and other issue that involve the patient's unstable or diminished integrative capacity. These conditions can disrupt processing of the traumatic memories or even increase fear of the memories and stronger inner conflict drives.

The modified imagery exposure of the Dynamic Therapy model is based on its two main components: guided synthesis and guided realisation of the memories. Guided synthesis involves modulated and controlled exposure to the traumatic memory in which the patient receives from the therapist to remain oriented and focused on the present time while synthesising the previously dissociative mental content of the traumatic memories. In essence, these represent affective, cognitive, sensorimotor, and behavioural components of the memories associated with various dissociative parts of the personality.

Guided realisation is an ongoing therapy process of helping the patient to realise the background of losses and suffering and move forward towards the higher levels of (adaptive) emotions, thinking, and behaviour. This cannot be expected to easily being admitted as the dissociative parts of personality may still have a strong power and show resistance to any changes. In line with these obstacles, the imagery exposure should demonstrate that the feared situation causes no harm. In such preparation, the patients are taught how to manage anxiety and fears of the traumatic memories and the inner impulses by using relaxation techniques and visualising a modified imagery which does not cause re-traumatisation. The patients recount the traumatic event(s) from the start to the end and imagine it as if it was happening again. They also experience the feelings they felt at the time when the trauma occurred, while recognising that they are in a safe environment (therapy session) and that the previous traumatic event(s) is now just a memory. They imagine the event again and again..., enough times until they are able to control the thoughts and the emotions related to the traumatic event.

Imagery exposure is useful when a traumatic memory remains vague, despite effort to recall it through the evaluation, description, exploration, or reflection of 
the traumatic past. With such repeated imagines, the patient learns that no harm can occur at the present time, even when he thinks about the event and imagine of being "present there again" with the same emotions and thoughts he has at the time when the trauma occurred. Despite the apparent simplicity in the imagery exposure, implementing such technique is not an easy task, as the exposure can be challenging. This therapeutic technique involves the patient's recounting of the upsetting thoughts and images, writing or reading scripts containing the distressing materials, or making a recording of the fear-provoking material that is replayed until a full habituation is fully achieved. This strategy allows the patient to confront an otherwise covert event and manipulation of the 'here-and-now' situation by the traumatic past. Moreover, the repetition of fear-evoking material (e.g., via recording) is helpful in a safety behaviour and ensures that the self-supervised (homework) exposure will incorporate confrontation with real trigger. Such trigger may revoke patient's traumatic memories; however, the patient's vulnerabilities are lesser and awareness of these memories does not make fear like before.

Most severely traumatised individuals report of having visual images of a danger in the post-trauma time, or even during the therapy. When asked about the details of the memories, they report visual images that have the same nature and general contents of the original trauma-that is one's anticipation of psychological trauma. Their fantasies and memories often represent a distortion of reality which makes the patient scream desperately for a help. It is common to find that the feelings associated with the fantasies are more congruent with fictitious perception than with reality. In many cases, patients report visualising a scene of trauma as though it were actually occurring again. Patients believe that these fantasies are real, identical with the traumatic past and, in essence, are one continuum that could be disbelieved.

These unrealistic pictorial images are so powerful that one believes in its authenticity which often misleads even the health professionals to think that the patient suffering from the hallucinations. Numerous patients with a history of severe traumatisation being referred to the therapy due to visual or olfactory hallucinations, as the patients complain of suffering unreal but authentic images leading to the conclusion that they were suffering from psychotic condition. The therapist who is dealing with complex trauma syndrome will realise the beliefs in fantasy varies from moment to moment and is unrealistic for the psychosis. Traumatised individuals totally or partially confuse the fantasy with the reality until some reality test or evaluation analysis the content of these images. Even though, the daydreams may be temporarily experienced as reality, the patients are able to regain their objectivity and label the phenomenon of fantasy (Beck et al., 2005). After analysing the nature of the fantasy, the fantasy can be experienced again, forcing the patient into a situation to test reality again.

Therapeutic approach in treating traumatic memories using imagery exposure is based on patient's experience of the fantasies of the traumatic event(s) vividly 
or in the other ways experienced. The exposure is focused on repeatedly experiencing such imaginings in safe, harmless, and controlled manner. It is a standard measure of systematic desensitisation by Wolpe (1969) and Lazarus (1972) to resolve the patient's fantasies of a traumatic moment. The content of the spontaneous images points to the cognitive distortions in a particular problem, and imagery procedures, such as an induced imagery, can help the patient alter spontaneous fantasies, reality-test, and to achieve distance from anxiety and fear (Beck et al., 2005).

In developing positive imagery, the therapist focuses attention on all sensual modalities: taste, smell, hearing, vivid visual details that may support the patient in experiencing a full, safe imagery exposure, such as described below:

Now, I want you to close your eyes and imagine yourself in a garden of your home on spring sunny day. You are sitting in a comfortable chair, drinking your favourite coffee, and watching a blossom in the neighbour's orchard. The sky is blue with a breeze and some clouds are floating above. You feel happy and fully relaxed. You smell the sweet smell of the grass. Your perpetrator is walking on the street with his head down avoiding eye contact with you. You can hear birds singing, short pure whistles like saying to your perpetrator he is a bad person. You can almost initiate them to sing that. Looking closer, you see your perpetrator's red sweaty face but you do not feel any hatred or hurt..., you just enjoy the sunny day. You feel completely calm and safe-just enjoy this scene for a few minutes.

Although the imagery scene requires from the patient to feel relaxed and moving thinking about the perpetrator and torture away, the therapist expects a lot of the patient's startle responses while mentioning the traumatic experience. It is common that during therapy the patient may stop imagery exposure due to the extreme reactions and feelings. Thus, the patient is encouraged to release and talk about feelings and thoughts during imagery. This feared event actually happened but the patient is helped to overcome his negative feelings and thoughts associated with it, without dreaded consequences suffered now. The imagery should be repeated with the homework practice and some new relaxing elements should be added to make patient more relaxed and safer.

One of the aims in working on traumatic memories is the cognitive reconstruction which helps in the development of the patient's self-awareness and restructure of negative thought processes. Reconstructing thoughts is a necessary step in correcting distortions, and when increasing self-awareness, the patient realises how sufficient it is to correct errors in thinking. Self-awareness allows the patient to distance himself from faulty thinking and to develop a more objective perspective towards situation (Beck et al., 2005; Herman, 1992; Zepinic, 2011). With reported negative thoughts, the therapist becomes more aware and understands the patient's vulnerability, weakness, and difficulties in controlling his emotions and thoughts associated with complex trauma syndrome. The therapist is often in quite difficult position of summarising all negative thoughts, 
as the trauma patient has experienced a lot of them. It is helpful to use a marker board to write them and then together with the patient categorise negative thoughts in order of their meaning to the patient. Frightening thoughts may cause other associated distortions of the emotions, behaviour, or relatedness, so that the patient should clarify which thoughts are the most frightening and that should be processed first.

Reconstruction is a process which actually transforms the traumatic memories and thoughts about them. The concept of thoughts reconstruction is based on "the action of telling the story" principle. Although traumatic memories are often wordless and deeply unconscious, the therapy overtakes a role as a "witness and ally" which encourages the trauma patient to speak freely and openly about something that seemed unspeakable. The therapist needs to clarify the severity of the meaning of negative thoughts to the patient so that more meaningful ones start to reconstruct. For success of the therapy, as well as to show respect for the patient's identification, the thoughts can be rated in accordance with the patient's opinion regardless of the eventual unreal categorisation.

With severely disturbed thoughts and feelings about the own self, we used reconstruction technique of the "mirroring". The "mirroring" is proto-conversation and primary intra-subjective that is attuned to the patient's present state. The role of vision is interaction with the "other", who is not able to respond or argue about the patient's narrative. The patient and the 'other' in the mirror have fixed eyes upon to each other. It is a matching process, which is not equivalent to imitation as the imitation is a static with nothing moving beyond it. In the other words, the mirroring is a dynamism between the patient and the "other" (Zepinic, 2011). It must be stated that imagery exposure, including mirroring, cannot start straightforward without the patient's readiness and willingness to do it.

Before commencing mirroring, the therapist should explain that the imagery exposure aims to reduce anxiety and fears associated with thinking about the traumatic event(s). With the patient, the therapist reviews a notion of "processing" the traumatic memories and addresses other aspects of the memories including those associated with anger and fears. Being fearful of releasing traumatic memories is a normal feeling in the severely traumatised individuals. However, as in early phase both the therapist and the patient already developed therapeutic relationship and the reassurance that the therapy sessions are a safe environment, the imagery exposure is one continuum of such relations despite the patient's question: "Do I really have to do it?". Once the distorted picture is fully recognised using imagery exposure, the patient then feels better and can handle situation more successfully without fears of the traumatic memories.

The work on traumatic memories using imagery exposure should start with the therapist's explanation of the methods and targeted goals:

Therapist: From today we will work on your traumatic memories which are significant part of your trauma experience. As usual, we will record our ses- 
sions but this time you will have the opportunity to listen again and again to each session at home as the records will be given to you. During review of the sessions you can make notes or drawing related to the remembered and released story.

Patient: I might start to cry and I will never stop.

Therapist: It is OK, to release memories and telling a story about the horror is not easy. Many patients also cried but did well and do not be ashamed of crying (reassurance, emphatic attunement).

Patient: Thank you doctor. I just know I do not like my past and I am scared of it, and I cannot stand fear (negative evaluation conditioning).

Therapist: It is quite reasonable to be afraid of revealing your traumatic memories (further emphatic attunement). We will work together. Monitoring your feelings and behaviour which are associated with traumatic memories will be my priority (further reassurance).

In the above sequences, it is evident that the patient's preparation to work on traumatic memories should be well oriented and grounded in a good and truthful relationship with the therapist. A carefully maintained approach helps the patient in taking a cognitive overview of the traumatic memories. This can be obtained from some functional part of the personality which is less dissociated and has no big impact on the patient's mental action. The therapist should closely observe eventual presence of any sign of an uncontrolled re-traumatisation. In the event of any re-experiencing of the flashbacks, the work on traumatic memories should be avoided. It is essential that the patient feels safe and that the level of arousal does not become too high and overwhelming. Fear and re-dissociation of the traumatic memories are common accompanying problems, as well as being stuck-up in the memory of one hypoaroused state. This should be controlled by therapist, and in a case of the re-dissociation appearance, the therapy should be switched to treat evoked dissociation.

Work on dissociation started in the early phase of treatment and should continue during mid-phase, in particular on those dissociative reactions with an amnesic state which usually disorient the patient. In this case, we asked patient to locate the last thing he remembers before the onset of amnesia. By repeating this procedure, we try to help patient to isolate the experienced indicators that signal the dissociative reactions. During therapy sessions, an experienced therapist may recognise typical manifestations of dissociation such as apparent forgetfulness about matters in therapy session, abrupt changes in the subject of disclosure, derailing of an ongoing conversation, the fears of distress, difficulties in the characterising alterations, changes in the attitudes, emotions, and viewpoint taken towards matters under discussion.

The most important task in treating dissociation in the mid-phase is further development of a sufficient trust and high empathic capacity. This task includes realisation of encapsulated, dissociative state by removing patient's maladaptive 
ego-defences and his insufficient information processing of the original traumatic experience, to facilitate the hierarchical integration of disintegrated parts of the personality, identity configuration, and dimensions of the self. When these interrelated processes of integration take adaptive stage, there is a natural and autonomic ability for the changes from the previously maladaptive affectivecognitive modalities of the functioning to an adaptive and functional self. It may be the case that knowledge of the transformative processes into positive, optimal state of the personality functioning is the archetypal expression of the human striving towards unity, integration, individuation, and self-actualisation (Wilson, 2006).

Van der Kolk et al. (1986) suggested that dissociated imprints of the traumatic memory sequences are retrieved as sensory fragments that have no connection or wholeness. Such dissociated fragments should be joined therapy as a coherent narrative memory of the traumatic experience. However, it is essential to avoid reconstruction of the traumatic experience based on the memory fragments, feelings, and fragmented perceptions. Initially, the incomplete and fragmented memory sequences may give wrong assumptions of the trauma patient's experience. Working on dissociation, the therapist faces variations of memory recall from time to time, more or less complete, that reflects defensive influences. Rosen (2004) stated that if the dissociation involves compartmentalisation and subsequent avoidance of the memories during a stressful experience, then rehearsal of the memories be effectively abolished.

Traumatised individuals with dissociation show chronic fears and anxiety, self-perception of poor physical and mental health, stress on important personal relationships, and a general sense of demoralisation and suicidality. Subjective perception of a life threat, perceived potential for physical violence, experience of extreme fear over the extended period of time and attribution of the personal helplessness are all contributing factors which lead to many severely traumatised individuals to developing dissociation. Zlotnick et al. (1999) found relationship between childhood sexual abuse and symptoms of hostility, somatisation, alexithymia, dissociation, social dysfunction, maladaptive schemas, self-destruction, and adult victimisation.

Horowitz \& Zilberg (1983) suggest that catastrophic event(s) contains internal and external information-most of them cannot be incorporated into the individual's ordinary cognitive schemas because they are outside the realm of a normal human experience. As this information cannot be integrated within the self, it is kept out of the conscious awareness, and remains in its unprocessed active form. Further work on the dissociation focuses on an integration of the disintegrated parts of the patient personality into a cohesive whole and more cooperation among the parts of personality.

Two characteristics of trauma experiencing should be taken into account in achieving these goals: a) most patients assume that the situation is safe in the absence of information signalling a danger; however, they never had enough 
safety signals to ensure that no danger exists and hence they are always alert, and b) some patients experience anxiety and discomfort at a high negative valance, so they are more likely to avoid situations that exacerbate their anxiety. The treatment also includes reassurance that each part belongs to the entire sense of self and aliveness/vitality. The dissociative parts of personality can be activated by various stimuli which often are not under patient's full control. This may lead to the maladaptive changes in the patient's basic emotions, goals, and behaviour; this is a problematic perception-motor action (Van der Hart et al., 2006). The maladaptive changes then bind any capacity in feared avoidance to the inner conflicts attached to dissociative parts of personality contributing to further decrease in levels of adaptive functioning.

Overcoming fears of dissociative parts of personality require a high level of engagement not only from the patient but from the therapist as well. All interventions should be designed to promote synthesis of the divided personality into one united part as a whole ("wholeness"). Trauma patients are unable or reluctant to recognise essential distortions in their personality because they are afraid to realise how distorted their thinking is that they cannot trust even their own thoughts, and the own self in general. As a result, they avoid 'remembering' what happened in the past blaming "amnestic state" for fragmented or limited recall of the trauma memories. They tend to compromise their senseless existence, aliveness or togetherness, spontaneity, and individuality. Traumatised patients may become exhausted in their struggle against the self-destructive urges and thoughts driven by the inner conflicts. The therapy should promote adaptive mental and behavioural actions that will help the personality to function as a whole system with interrelated and interconnected functional parts (Zepinic, 2016b).

\section{c) Final phase of treatment}

The final phase of treatment includes self-conception, enhancing daily living, and relapse prevention. Goals in therapy should always be patient-directed, no matter how well trained and skilled the therapist is or, how extensively he may desire to "reconstruct" the patient's personality. In the final phase of treatment, therapeutic gaols shift to the self-development, adaptations to normal life, and relationships. Although the previous two phases reduce symptoms and resolve dissociation and traumatic memories, the patient's full engagement in living is not achieved if the final phase is not accomplished. Trauma patients who are more able to construct the meaningful and realistic attitudes in the wake of the traumas are more successful in overcoming their traumatic experience. The remaining trauma-related beliefs and cognitive distortions related to the trauma are both addressed in the final phase of treatment.

Therapy is not a linear process and, frequently during the final phase, new memories or previously unidentified fragments of the memory may arise, perhaps due to the patient's increased integrative capacity that enables control of the previously dissociated memories (Steele et al., 2005). It is not surprise that, 
after two successful phases of treatment, the patient may feel satisfied with the progress and concludes that a further therapy is not necessary. This fact has confounded many therapists. However, the disintegrative force within the personality may be so strong as to threaten to break apart all adaptive self-structure if treatment stops prematurely. The trauma patient has an insufficient level of mental energy to integrate the traumatic past, and the levels of present functioning are still influenced by the horrors of the past. Free from traumatic memories, the patient enters into the final phase with a requirement for more adaptive actions.

The final phase of treatment is a period when the haunted self should be finally restored to its pre-trauma levels of the self-continuity and self-cohesion. With increased integrative capacity, the trauma patient is able to better tolerate arousal, and he is ready for new connections to overcome fears of daily life, evaluate, take appropriate risks, and explore the changes of the divided personality. In the final phase, patient begins to develop other neglected areas of personality and functioning such as professional and occupational needs, or his social belonging. The patient's changes in cognitive distortions and corresponding physical tendencies are in focus alongside with establishing a new or repair old relatedness. It is also evidenced that trauma patients are keen to sustain engagement in activities they found meaningful and pleasurable.

As the severe trauma could shatter all structure of the self and its coherence and continuity, the therapy is faced with a question of how to help trauma patient to transform such powerful and life-threatening experience into a positive way. During the final phase, the therapy provides helpful structures as the patient practices new interpersonal and intrapsychic patterns, moving from a baseline of friendliness towards the self and others that include degrees of independency. In addition, it is a good balance between focus on self and focus on others. Thus, the transformation process that occurs in the nature of trauma results in an integrated and reinvented self with the whole structure from dissociated and disconnected parts, one that is more grounded, centered, and connected to its values. The self then becomes functional and higher state of the consciousness less impacted and parted by the inner conflicts and their drives.

The transformation of one's self will influence not only therapeutic framework (in content of traumatised self-interpretation), but also the therapist's general attitudes towards achieving the desired goals-the patient's entire recovery from the trauma. The point of view taken with regards to such seemingly focused target is how much trauma patient still feels helpless and dysfunctional. With significantly improved functioning of the self-structure and being powerful with control of the inner conflicts, the question is whether the trauma patient is himself-or whether the self will remain always in some stage of depletion and division. In principle, the cohesive structure of the patient's personality tends to emerge optimally in a new environment. Having developed in collaboration and insight, the patient is able to review specific current relatedness in the light of 
input, response, and impact on the self. After recognising these connections, the patient anticipates the needs to block eventual repetition of the past patterns.

The final phase of therapy supports patient's self-discovery in a) accepting what it was and what it is and moving forward, and b) making mindful and benevolent choices (Zepinic, 2016b). Self-discovery activities mostly focus on maintaining the motivation to move beyond the traumatic past. This phase of the treatment to help the self-management is based on a) identifying and practicing new, constructive patterns, and b) resisting the wish to go back to old ways of management influenced by the inner impulses and traumatic past. However, the patient may express some "fear of newness and progress achieved" which indicates patient's uncomfortable feelings of the "newness" due to accustomed loss of habitual ways that he practiced for so long after trauma experience.

The traumatised individual's major maladaptive assumption about others is often centred around the acceptance, competence, and control which determine the patient's sense of vulnerability of an acceptance by the others. Many fears of new relatedness might be better understood when the patient looks at the standpoint of these three issues and responses received from others. The fear of relatedness may be a result of fear that other people will reject the patient to get close or that others will control patient, or that he is not able to reach their expectations, or they might demand standards of behavioural and achievements. While transforming the patient's relatedness, the therapy should change or modify the underlying beliefs that predispose the patient to the fears and anxiety of relatedness. In the process of collecting negative thoughts related to the expectations, the therapist intends to change the patient's views of the world. Therapy uses a deductive method which starts exploring the patient's feelings and behaviours, and then moves to the automatic thoughts and to the assumptions behind the thoughts, and finally arrives at the patient's major concerns (Beck et al., 2005).

The therapy uses different methods to identify patient's negative assumptions in an attempt to reduce tension and the influence of maladaptive thoughts, emotions, and behaviour. It is aimed to achieve new coping strategies that will be outside the influence of the inner conflict drives, divided and split personality. The therapy is focused on modifying and reformulating assumptions to find how they may fit to the adaptive relatedness. This can also be done by using imagery exposure as a method to train the patient to accustom himself to demands from the external work (Zepinic, 2008). For example, therapist asks patient to close his eyes and picture the pre-trauma memories and implement them in "here-and-now" environment.

Therapist needs to give an encouragement to the patient to recall the experiences in which pleasant relationships with others had dominated. It is almost common that patient is able to have a vivid image of some positive relationships with others that strictly can be imagined to the present time. The patient is asked 
to concentrate on one which could best recall and which had a significant influence on his relatedness. Then, the therapist and patient work together on imagined pre-trauma relatedness, putting together strategies for the present time in a meaningful way (Zepinic, 2011, 2016b). The patient is then asked to release feelings, thought, and/or body sensations associated with the early experienced relatedness and compare them with what he is experiencing at the present time. This procedure helps the patient to see how his traumatic memories from the past create problems in the patient's present relatedness and the way to a future happiness. Most patients succeed with their imagination of the previous relatedness in identifying feelings and contents of the feared present problems in forming new relatedness.

Patient's assumptions toward others are usually identifiable because he repeats the same patterns all the time. Further, his assumptions usually have a long history of existence and are resistant to the changes. To be effective, the therapist has to address the basic issues of relatedness which are easier to correct and which are less influenced by maladaptive thoughts and emotions.

The core concern of the traumatised patient regarding acceptance by others is that he will be rejected in some ways by them. The development of disbelief dates back to the time of trauma experience when the patient had been overpowered, rejected, defeated, helpless, and pressured. In post-trauma time, he has a stigma or flaw that makes him unacceptable to the others. The patient may use a variety of strategies to get others to accept and love him unconditionally, but he is often terrified of rejection. He wants to please others and, because he feels unacceptable and unwanted, he has been terrified of being alone and constantly seeks attachment and relatedness. The patient may exaggerate the extent and significance of the social acceptance or rejection. Because the others opinions directly affect self-values, patient is a highly dependent on feedback from others and continue checks the possibility of acceptance. In case that he receives a positive feedback from others, the patient becomes more confident and generally performs better (Beck et al., 2005; Courtois \& Ford, 2009, Ford et al., 2005). However, in the event of others rejecting him, the patient's confidence goes down and his performance inevitable deteriorates.

The integration does not occur automatically during the final phase of treatment and the regression, which is an exact repetition of the pre-treatment comorbid condition with the overwhelming feelings, projective mechanisms, and loss of relatedness and self-continuity, may occur. These regressive episodes, however, cannot lasts as it was before the treatment or have a similar influential impact on the traumatised personality. The trauma patient is now capable of working on the restoration of disrupted condition easily and successfully.

In case of regressive episode, it is usually a short-lasting and does not block posttraumatic growth or shift into an opposite site causing split-off of the patient's personality. The therapy process of reintegration and restoration of the regressive materials is much easier and more acceptable. The patient does not 
show resistance to the changes, nor experiences fears and anxiety. In fact, the patient can shift rapidly from the regressive episodes into an integrated stage by a) recognition of the dominant object relations to b) the definition of self and object representation and their interchange in the transference, and to c) the integration of split-off dyads with the integration of the self-representation into an integrative self and integrated concept of others (Zepinic, 2016b).

Integration into an integrated concept is a conscious process that the patient cherished with the therapist's support and their confident therapeutic relationship. The patient comes into the final phase of the treatment becoming more capable, relieved, valuable, affectionate, hopeful, relaxed, and courageous. It is expected that some "residual" sequences of trauma will be sufficiently resolved completely and that the patient's pattern of "acting out" is under control. However, the patient should be aware that "acting out" behaviour is a significant risk for the regression or the relapse of condition. The crisis may occur in the event of some pressure, internal or external, which unbalances the personality system and the patient's learnt coping systems are unable to restore the psychic homeostasis. Such crisis and "acting out" should be closely observed as restoration of the equilibrium is quite important.

Prevention of the patient's "acting out" behaviours should focus on narratives about the doubtful feelings and the patient's strength and ability to cope with the life situations. A viable recognition of reality should be developed and replaced with often intense and unrealistic initial fusion, which is driven by the patient's desperate or premature needs and hopes. It is also needed to explore the patient's personality system to tolerate stressful situation and the steps needed to be taken to avoid the crisis. The patient needs to be taught that difficulties out of the therapy may have some painful impacts on the therapy progress and patient's posttraumatic growth. Highly disorganised patients with broken relationships and lost faith in the outer world may not be able to find internal resources to cope with the crisis without support. They cannot regain self-control and may experience significant anxiety and fears that therapy progress has deteriorated.

Any crisis that is an aftermath of the patient's distressing behaviour demands a great availability and involvement of the therapist. In resolving these issues, the therapist should gather as much information as possible about the precipitating circumstances of the crisis and the patient's response. There is no doubt that self-containment can be under test and requires self-restrain, however, if the self-containment fails, the patient needs external containment which, in essence, the therapy provides. The self-containment is a process of holding back full expression of the emotions and enables the patient of full expression of the emotions (Allen, 2005; Ulman \& Brothers, 1988). The internal containment stems from the compassionate relationship with the own self and capacity to mentalise various forms of the self-regulations. External containment stems from the supportive relationships and secure attachments which the therapeutic alliance pro- 
vides. The final phase of treatment focuses more on internal containment (selfcontainment) and less on external containment.

As often be said, planning for the ending therapy should occur from the beginning of the treatment. Practically, it is in the therapeutic plan to achieve reasonable healing and recovery, and to accomplish therapeutic goals so that therapy can be ended. At the end of the therapy, we proposed that the psychological intervention rests on three fundamental assumptions for the traumatised patient: the world is meaningful, the world is benevolent, and the patient's self is worthy.

As all roads lead to Rome, it is always a question for how long psychological intervention lasts. At the present, there is no consensus regarding the ideal duration of the treatment or its specific course. ISTSS guideline (Cloitre et al., 2012) for complex PTSD suggests that treatment varies depending on severity and complexity of symptom, but in general should last around 2 years. The guideline recommends 6 months a reasonable length of time for phase 1,3-6 months for phase 2, producing combined treatment duration 9 - 12 months for the first two phases. Phase 3 should take 6 - 12 months with less frequent therapy sessions than in first two phases. Decision about the duration of each phase of treatment, in general, is the clinician's judgment about the patient's progress and symptoms remission. It should be noted that for some complex PTSD cases, the duration of the intensive treatment phases ( 1 and 2 ) may be necessary for periods significantly longer that the estimated 12 months. For severely impaired patients, treatment of several years may be necessary and/or may be required intermittently over the individual's lifetime (Cloitre et al., 2012).

\section{Conclusion}

Severe trauma such as the war combat, being taken as a hostage, brutal or repeated rape, affects all structures of the victim's personality. Trauma overwhelms the ordinary human adaptation and resistance as it is usually the threat to life or bodily integrity and confronts the victim with feelings of powerlessness, hopelessness, and helplessness. The psychological sequelae following traumatic experience are usually a domino-like progression of the stress-response reactions. In case of severe trauma, the personality suffers alteration of the self-cohesion and self-continuity. The process of disintegration of the victim's self occurs in two ways: a) consciously expressed concerns related to weak, vulnerable, defenceless, and defective sense of self, and b) out of the victim's conscious awareness, disintegrated and disjoined self is seen as a danger to the traumatised person and to the others (Zepinic, 2016a). As a consequence of the self-discontinuity, the trauma victim is flooded with intrusive memories of the traumatic experience, as well as distorted thoughts, images, and self-values with compounded levels of hyperarousal or flashbacks (Van der Hart et al., 2006; Zepinic, 2012).

Treating complex stress disorder is very complex issues, in particular using the standard therapies recommended for treating PTSD. The standard practice 
of debriefing after either natural or man-designed disasters or catastrophes (e.g., terrorist attack, combat experience, brutal rape) that cause severe fears and phobias, could strike further development of complex stress-related condition because of re-occurrence of the fresh traumatic memories. To explain trauma symptoms of complex trauma, it is important to consider how much exposure to a life-threatening situation became conditioned to a wide variety of stimuli during traumatic event(s). As severe trauma inflicts a terror and fears which are increased by the inconsistent and unpredictable outbursts of the enforcement against the victim's personality, the trauma may lead to the losses of one's autonomy and all aspects of the independent functioning, even basic desire to survive.

The clinicians are of opinion that trauma-focused therapeutic approach is more effective in treating complex PTSD that the other therapy models. There are around 40 different types of treatments of psychological trauma, although most of them are focused on the CBT model. The Dynamic Therapy model has been developed as a result of a decade of research and therapy experience in providing treatment to the severely traumatised individuals (Zepinic, 2011). It is a broad conceptual model that integrates the knowledge of the multidimensional nature of complex trauma. The model, rather a process than a special technique, is multi-modal system and originally casts as the trauma-focused narrative, behavioural, cognitive, and analytic approach. The main concept of the Dynamic Therapy model is in providing three-phased therapy with and without to the patients focussing attention upon symptoms and behaviours, and one's destructed sense of personal being. The therapy is directed towards restoration of a disrupted sense of self that affects the inner and the outer world of the traumatised individual.

The meanings of the Dynamic Therapy model include the clinician's sensitivity for the patient's problems, respect for severity and frequency of trauma symptoms, disposition of empathy, valuing subjectivity and conscious state, and the capacity for attachment and fundamental grounds for the patient's security. The model is in essence explorative and supportive, challenging process with importance of therapeutic relationships. It should be not time and sessions limited but the timeframe is guided by the level of trauma symptoms and the patient's dysfunctional state (Zepinic, 2011).

Dynamic Therapy is a multimodal system and originally casts as the cognitive-behavioural-analytical approach; it is a long-term three-phased individual therapy (one year as the minimum) designed to treat complex PTSD. The goals of therapy are achieving an emotional and cognitive regulation, inter and intrapersonal effectiveness, tolerance to distress imposed by the inner conflict drives and traumatic memories, and coping strategies and self-management.

The Dynamic Therapy theoretical construct deals with the following concepts: 1) nature of the predisposing factors in complex trauma, 2) the manner in which the trauma experience and conditioning produce distortions in the trauma vic- 
tim's personality, 3) the relationship between the personality structure and trauma, 4) the constituents of inner conflicts, 5) the meaning, function and manifestations of the trauma syndrome, 6) the structure of the psychic apparatus, and 7) the mechanism of defences. Dynamic Therapy model aims three main goals: 1) restoration of a form of relatedness (Interconnectivity), 2) restoration of a sense of aliveness/vitality (Dynamism), and 3) restoration of an awareness of self and inner events (Insight). The Dynamic Therapy model applies to the holotropic (oriented towards wholeness or moving in the direction of wholeness) integration of the consciousness.

\section{Acknowledgements}

The author thanks to all his patients from whom he learned more than he can ever say or thank.

\section{Conflict of Interest}

There is no conflict of interest regarding this article, and the article has not been supported by any foundation.

\section{References}

Allen, J. G. (2005). Coping with Trauma. Washington DC: American Psychiatric Press.

APA, American Psychiatric Association (1980). Diagnostic and Statistical Manual of Mental Disorders (3rd Edition). Washington DC: APA.

APA, American Psychiatric Association (2013). Diagnostic and Statistical Manual of Mental Disorders (5th Edition). Arlington: APA.

Banyard, V. L., \& Williams, L. M. (1998). Trauma and Memory. London: Sage.

Beck, A. T., Emery, G., \& Greenberg, R. L. (2005). Anxiety Disorders and Phobias: A Cognitive Perspective. New York: Basic Books.

Bisson, J. I., Ehlers, A., Matthews, R., Pilling, S. et al. (2007). Psychological Treatments for Chronic Post-Traumatic Stress Disorder. British Journal of Psychiatry, 190, 97-104. https://doi.org/10.1192/bjp.bp.106.021402

Boss, P. (2006). Loss, Trauma, and Resilience. New York: WW Norton.

Briere, J., \& Spinazola, J. (2009). Assessing the Sequelae of Complex Trauma. In A. C. Courtois, \& J. D. Ford (Eds.), Treating Complex Traumatic Stress Disorders. New York: The Guilford Press.

Burgess, A. W. et al. (1985). Rape and Sexual Assault. New York: Garland.

Clark, D. A. (2004). Cognitive Behavioural Therapy for OCD. New York: The Guilford Press.

Cloitre, M., Courtois, C. A., Ford, J. D., Green, B. L. et al. (2012). The ISTSS Expert Consensus Treatment Guidelines for Complex PTSD in Adults. Washington DC: APA.

Courtois, A. C., \& Ford, J. D. (2009). Treating Complex Traumatic Stress Disorders. New York: The Guilford Press.

Duckworth, M. P., \& Follete, V. M. (Eds.) (2012). Retraumatisation: Assessment, Treatment, and Prevention. New York: Routledge.

Ehlers, A., \& Clark, D. M. (2000). A Cognitive Model of Posttraumatic Stress Disorder. 
Behaviour Research and Therapy, 38, 319-345.

https://doi.org/10.1016/S0005-7967(99)00123-0

Erikson, E. H. (1968). Identity, Youth \& Crisis. New York: WW Norton.

Foa, E. B., \& Rothbaum, O. B. (1998). Treating the Trauma of Rape. New York: The Guilford Press.

Foa, E. B., Keane, T. M., \& Friedman, M. J. (2009). Effective Treatments for PTSD. New York: The Guilford Press.

Ford, J. D. (2009). Dissociation in Complex Posttraumatic Stress Disorder or Disorders of Extreme Stress Not Otherwise Specified (DESNOS). In P. F. Dell, \& A. J. O’Neil (Eds.), Dissociation and the Dissociative Disorders. New York: Routledge.

Ford, J. D., Courtois, A. C., Steele, K., van der Hurt, O., \& Nijenhuis, E. R. S. (2005). Treatment of Complex Dysregulation. Journal of Traumatic Stress, 5, 437-447. https://doi.org/10.1002/jts.20051

Herman, J. L. (1992). Trauma and Recovery. New York: Basic Books.

Horowitz, J. P., \& Zilberg, N. (1983). Regressive Alterations in the Self-Concept. American Journal of Psychiatry, 140, 284-289. https://doi.org/10.1176/ajp.140.3.284

Horowitz, M. J. (1978). Stress Response Syndrome. Northvale: Jason Aronson.

Hyer, L., McCranie, F. M., Boundewyns, P. A., \& Sperr, E. (1996). Models of Long-Term Coping Trauma Memories: Relative Use and Associations with Personality among Vietnam Veterans Chronic PTSD. Journal of Traumatic Stress, 9, 299-316. https://doi.org/10.1002/jts.2490090211

Lazarus, A. A. (1972). Behaviour Therapy and Beyond. New York: McGraw-Hill.

Meares, R. (1987). The Secret and the Self: One New Direction in Psychotherapy. Australian and New Zealand Journal of Psychiatry, 21, 545-559. https://doi.org/10.3109/00048678709158923

Ogden, P., Minoth, K., \& Pain, C. (2006). Trauma and the Body. New York: WW Norton.

Putnam, F. W. (1989). Diagnosis and Treatment of Multiple Personality Disorder. New York: The Guilford Press.

Resick, P. A., \& Schnicke, M. K. (1992). Cognitive Processing Therapy for Sexual Assault Victims. Journal of Consulting and Clinical Psychology, 60, 748-756. https://doi.org/10.1037/0022-006X.60.5.748

Rosen, G. M. (2004). Posttraumatic Stress Disorder, Issues and Controversies. Chichester: Wiley \& Sons. https://doi.org/10.1002/9780470713570

Silova, D. (2002). The Asylum Debacle in Australia: A Challenge for Psychiatry. Australian and New Zealand Journal of Psychiatry, 2, 90-96. https://doi.org/10.1046/j.1440-1614.2002.01036.x

Steele, K., van der Hart, O., \& Nijenhuis, E. R. S. (2005). Phase Oriented Treatment of Structural Dissociation in Complex Traumatisation: Overcoming Trauma-Related Phobias. Journal of Trauma and Dissociation, 6, 11-53.

https://doi.org/10.1300/J229v06n03_02

Stern, D. N. (2004). The Present Moment. New York: WW Norton.

Summerfield, D. (2001). Asylum-Seekers, Refugees and Mental Health Services in the UK. Psychiatric Bulletin, 1, 61-63. https://doi.org/10.1192/pb.25.5.161

Ulman, R. B., \& Brothers, D. (1988). The Shattered Self: A Psychoanalytic Study of Trauma. Hillsdale: The Analytic Press.

Van der Hart, O., Nijenhuis, E. R. S., \& Steele, K. (2006). The Haunted Self. New York: WW Norton. 
Van der Hart, O., Steel, K., Boon, S., \& Brown, P. (1993). The Treatment of Traumatic Memories: Synthesis, Realisation, and Integration. Dissociation, 1, 62-80.

Van der Kolk, B. A., \& Courtois, C. A. (2005). Editorial Comments: Complex Developmental Trauma. Journal of Traumatic Stress, 3, 83-85.

Van der Kolk, B. A., MacFairlane, A., \& Weiseath, L. (1986). Traumatic Stress. New York: The Guilford Press.

Wilson, J. P. (Ed.) (2006). The Posttraumatic Self. New York: Routledge.

Wilson, J. P., \& Drozdek, B. (Eds.) (2004). Broken Spirit. New York: Brunner-Routledge.

Wolpe, J. (1969). The Practice of Behaviour Therapy. New York: Penguin Books.

Zepinic, V. (1997). Psychosocial Characteristics of War-Related Posttraumatic Stress Disorder (Chapter 10). In B. Ferguson, \& D. Barnes (Eds.), Perspectives on Transcultural Mental Health (pp. 85-93). Sydney: TCMHC.

Zepinic, V. (2001). Suicidal Risk with War-Related Posttraumatic Stress Disorder (Chapter 14). In B. Raphael, \& A. E. Malak (Eds.), Diversity and Mental Health in Challenging Times (pp. 212-221). Sydney: TCMHC.

Zepinic, V. (2004). Treatment Resistant Symptoms of War-Related PTSD. Paper Presented at $18^{\text {th }}$ World Congress of World Association for Social Psychiatry, Kobe.

Zepinic, V. (2008). Healing Traumatic Memories: A Case Study. Dynamische Psychiatrie, 2, 79-87.

Zepinic, V. (2010). Treating the War-Related Complex Trauma Using Dynamic Therapy. The International Journal of Medicine, 3, 84-90.

Zepinic, V. (2011). Hidden Scars: Understanding and Treating Complex Trauma. London: Xlibris.

Zepinic, V. (2012). The Self and Complex Trauma. London: Xlibris.

Zepinic, V. (2015). Treatment Resistant Symptoms of Complex PTSD Caused by Torture during War. Canadian Social Science, 9, 26-32.

Zepinic, V. (2016a). Disintegration of the Self-Structure Caused by Severe Trauma. Psychology and Behavioural Sciences, 4, 83-92. https://doi.org/10.11648/j.pbs.20160504.12

Zepinic, V. (2016b). The Dynamic Therapy Model in Treating Complex Trauma Syndrome. Studies in Sociology of Sciences, 4, 1-18.

Zepinic, V., \& Kuzmanovski, B. (2015). Support Person (Co-Therapist) in the Therapy of Panic Disorder. Canadian Social Science, 12, 1-7.

Zlotnick, C., Warshaw, M., Shea, M. et al. (1999). Chronicity in Posttraumatic Stress Disorder (PTSD) and Predictors of Course of Comorbid PTSD in Patients with Anxiety Disorders. Journal of Traumatic Stress, 12, 89-100.

https://doi.org/10.1023/A:1024746316245 